\title{
Tecnologias sociais e resíduos sólidos: catalogação de experiências em cooperativas e associações de catadores de materiais recicláveis e um retrato da Amazônia brasileira
}

\author{
Social technologies and solid waste: cataloging experiences in cooperatives and associations of
} recyclable materials collectors and a portrait of the Brazilian Amazon

Tecnologías sociales y residuos sólidos: experiencias de catalogación en cooperativas y asociaciones de recolectores de materiales reciclables y un retrato de la Amazonía brasileña

Recebido: 21/01/2022 | Revisado: 25/01/2022 | Aceito: 02/02/2022 | Publicado: 04/02/2022

Lucilla Raphaelle Carmo Castro

ORCID: https://orcid.org/0000-0003-2284-5912 Instituto Federal de Educação Ciência e Tecnologia do Pará, Brasil E-mail: leluci.castro@gmail.com

Flávia Augusta Miranda Lisboa ORCID: https://orcid.org/0000-0002-6370-5222 Instituto Federal de Educação Ciência e Tecnologia do Pará, Brasil E-mail: flavia.lisboa@ifpa.edu.br

Ingrid Tatiany Ribeiro Gomes de Souza

ORCID: https://orcid.org/0000-0003-0843-5597 Instituto Federal de Educação Ciência e Tecnologia do Pará, Brasil E-mail: isouzam@hotmail.com

\begin{abstract}
Resumo
Este estudo objetivou realizar a construção de uma matriz analítica regionalizada das experiências brasileiras de Tecnologias Sociais (TS) no âmbito das cooperativas e associações de catadores de materiais recicláveis, destacando a realidade amazônica observada a partir da matriz construída. Para tanto, a coleta de dados foi realizada por meio da utilização de palavras-chave em dois bancos de dados: Fundação Banco do Brasil (FBB) e o Google Acadêmico (Google Scholar). Do total das TS investigadas, identificou-se que 17 foram desenvolvidas por, ou em conjunto com as cooperativas/associações. Os principais entraves identificados para a implantação das TS, ou durante o processo, foram relacionados a quatro eixos: econômico, ambiental, institucional e social. A respeito dos principais avanços que as TS catalogadas alcançaram estão: a formalização de cooperativas; a capacitação dos trabalhadores envolvidos; desenvolvimento de programas de compostagem; mobilização da comunidade; otimização dos processos de coleta e reciclagem; implantação/ampliação da coleta seletiva; correta destinação dos resíduos; melhoria de qualidade de vida e significativo aumento da renda dos cooperados. Em relação a Amazônia brasileira, das 17 TS catalogadas, somente três experiências estão situadas na região (aproximadamente 18\% do total). Os baixos percentuais de TS identificadas na Amazônia, escancaram a comprovada ineficiência na integração estratégica dos diferentes atores: Estado, organizações privadas e comunidade. Integração essa, de extrema importância para a eficiência no desenvolvimento e aplicação de TS que proporcionem reais benefícios para a população envolvida.
\end{abstract}

Palavras-chave: Tecnologias sociais; Cooperativas e associações; Resíduos sólidos; Amazônia.

\begin{abstract}
This study aimed to build a regionalized analytical matrix of Brazilian experiences in Social Technologies (TS) within the scope of cooperatives and associations of recyclable material collectors, highlighting the Amazonian reality observed from the constructed matrix. Therefore, data collection was performed using keywords in two databases: Fundação Banco do Brasil (FBB) and Google Scholar (Google Scholar). Of the total of investigated STs, it was identified that 17 were developed by, or in conjunction with, cooperatives/associations. The main obstacles identified for the implementation of STs, or during the process, were related to four axes: economic, environmental, institutional and social. Regarding the main advances that the cataloged TS have achieved are: the formalization of cooperatives; the training of the workers involved; development of composting programs; community mobilization; optimization of collection and recycling processes; implementation/expansion of selective collection; correct disposal of waste; improvement in the quality of life and significant increase in the cooperative members' income. Regarding the Brazilian Amazon, of the 17 TS catalogued, only three experiences are located in the region (approximately $18 \%$ of the total). The low percentages of SW identified in the Amazon reveal the proven inefficiency in the strategic integration of different actors: State, private organizations and community. This integration is extremely important for the efficiency in the development and application of ST that provide real benefits for the population involved.
\end{abstract}

Keywords: Social technologies; Cooperatives and associations; Solid waste; Amazon. 


\begin{abstract}
Resumen
Este estudio tuvo como objetivo construir una matriz analítica regionalizada de experiencias brasileñas en Tecnologías Sociales (TS) en el ámbito de las cooperativas y asociaciones de recolectores de materiales reciclables, destacando la realidad amazónica observada a partir de la matriz construida. Por lo tanto, la recolección de datos se realizó utilizando palabras clave en dos bases de datos: Fundación Banco do Brasil (FBB) y Google Scholar (Google Scholar). Del total de TS investigados, se identificó que 17 fueron desarrollados por, o en conjunto con, cooperativas / asociaciones. Los principales obstáculos identificados para la implementación de las TS, o durante el proceso, se relacionaron con cuatro ejes: económico, ambiental, institucional y social. En cuanto a los principales avances que han logrado los TS catalogados son: la formalización de las cooperativas; la formación de los trabajadores implicados; desarrollo de programas de compostaje; Movilización comunitaria; optimización de los procesos de recolección y reciclaje; implementación / expansión de la recolección selectiva; eliminación correcta de residuos; mejora de la calidad de vida y aumento significativo de los ingresos de los cooperativistas. En cuanto a la Amazonía brasileña, de las 17 TS catalogadas, solo tres experiencias se ubican en la región (aproximadamente el 18\% del total). Los bajos porcentajes de SW identificados en la Amazonía revelan la probada ineficiencia en la integración estratégica de diferentes actores: Estado, organizaciones privadas y comunidad. Esta integración es de suma importancia para la eficiencia en el desarrollo y aplicación de TS que brindan beneficios reales para la población involucrada.
\end{abstract}

Palabras clave: Tecnologías sociales; Cooperativas y asociaciones; Residuos sólidos; Amazonas.

\title{
1. Introdução
}

De acordo com os dados do panorama da Associação Brasileira de Empresas de Limpeza Pública e Resíduos Especiais (ABRELPE), em 2019 no Brasil foram geradas 79.069.585 toneladas de Resíduos Sólidos Urbanos (RSU). Na última década essa geração no país cresceu em torno de $19 \%$ enquanto o volume de resíduos sem destinação final adequada aumentou em torno de 30\% no mesmo período, revelando assim um setor carente de investimentos e políticas eficientes, onde diversos autores afirmam que a problemática envolvendo os resíduos sólidos (RS) nas últimas décadas tem gerado impactos severos não somente na dimensão ambiental, mas também implicações diretas na área social, econômica e institucional (ABRELPE, 2020; Oliveira \& Galvão Jr, 2016; Santiago \& Dias, 2012).

Em 2010 através da Lei 12.305, foi instituída a Política Nacional de Resíduos Sólidos (PNRS) no Brasil, que além de trazer definições e conceitos importantes relacionados à gestão dos RS tem princípios associados ao desenvolvimento sustentável, visando não somente melhoria da gestão e do gerenciamento dos resíduos no país, mas também mudanças de hábitos da população e de seus governantes (Brasil, 2010; Veiga et al., 2016).

Entre os instrumentos da PNRS está o incentivo à criação e ao desenvolvimento de cooperativas ou de outras formas de associação de catadores de materiais reutilizáveis e recicláveis. Para Golveia (2012), pode-se considerar os catadores de materiais recicláveis como os grandes protagonistas da indústria de reciclagem no Brasil, salientando a dificuldade de incluir no gerenciamento de RS as atividades de catação, principalmente por problemas na escala de produção combinados a dificuldades logísticas.

Para Arantes e Oliveira (2013), os trabalhadores que atuam em contato direto com o material descartado pela população acabam sendo estigmatizados e marginalizados pela sociedade, além de enfrentar extensas jornadas e condições precárias de trabalho e baixa renda. Assim, a consolidação de associações e cooperativas compostas por estes trabalhadores almeja a melhoria das condições de trabalho e por consequência da qualidade de vida dos mesmos (Gonçalves \& Silva, 2009).

Nas últimas décadas no Brasil e no mundo, um movimento de caráter social ganhou força e está avançando com o objetivo de proporcionar às pessoas mais necessitadas a melhoria da sua qualidade de vida por meio do desenvolvimento tecnológico, esse movimento é denominado pelo termo "tecnologia social" (Castro et al., 2020).

Diferentemente de outras técnicas, uma das bases da TS é a participação dos indivíduos locais nas diferentes etapas de sua implantação, tendo por finalidade a inclusão socioambiental que essas tecnologias se propõem a resolver (Baumgarten, 2006; Gualdania \& Sales, 2016). Dessa forma, este conceito engloba o vínculo entre as universidades, institutos de pesquisa e a comunidade. 
A combinação do conhecimento acadêmico e popular é a chave para a melhor compreensão do conceito, e assim implementação de soluções simples para problemas do cotidiano da população já que a TS envolve baixo custo de implementação e alto potencial transformador (Seixas et al., 2015). Observa-se, assim, que as TS nascem de uma necessidade específica de uma população ou comunidade. São metodologias, produtos ou técnicas desenvolvidas em conjunto entre a população e uma equipe técnica para resolver uma determinada questão. Há troca de conhecimentos e saberes, nenhuma aplicação é imposta, todo o desenvolvimento é conjunto, sempre preservando as características, materiais e mão de obra disponíveis localmente. Somado a isso há a expectativa das pessoas que serão atendidas.

As bases conceituais, teóricas e experimentais que compõem o âmbito da Tecnologia Social (TS), que é definida pelo Instituto de Tecnologia Social (ITS) como "um conjunto de técnicas, metodologias transformadoras, desenvolvidas e/ou aplicadas na interação com a população e apropriadas por ela, que representam soluções para a inclusão social e melhoria das condições de vida" (ITS, 2007). são trazidas para esta pesquisa de maneira a fomentar novas reflexões em torno da sua efetividade, pertinência e viabilidade, uma vez que esta área de conhecimento possui propostas conceituais altamente integradoras (Zucoloto \& Pereira, 2017) e diferenciam-se amplamente das ditas tecnologias convencionais, que são aquelas desenvolvidas visando exclusivamente o lucro, por buscarem alternativas modernas, simples e com custo baixo para a solução de problemas estruturais das camadas mais excluídas da sociedade (Costa, 2013).

Diante da conturbada realidade em diferentes dimensões vivenciada pelos trabalhadores que atuam na atividade da catação de materiais recicláveis no Brasil, surgem os questionamentos: de qual maneira a aplicação de TS no âmbito de cooperativas e associações de catadores reverte-se em benefícios socioeconômicos aos catadores e suas famílias? Se assim ocorre, essas experiências representam o resgate de dignidade e qualidade de vida para os envolvidos?

Dessa forma o objetivo desta pesquisa é construir uma matriz analítica regionalizada das experiências brasileiras de TS no âmbito das cooperativas e associações de catadores de materiais recicláveis, destacando a realidade amazônica observada a partir da matriz construída.

\section{Metodologia}

\section{1 Área de Estudo}

O enfoque da pesquisa foi catalogar experiências de TS em todo o território brasileiro, observando-se todas as regiões (Norte, Sul, Sudeste, Nordeste e Centro-Oeste), entretanto, destacou-se a Região Amazônica na discussão dos resultados. A região em questão, que também é chamada de Amazônia Legal ou Amazônia Brasileira (Figura 1), está sob atuação da Superintendência de Desenvolvimento da Amazônia (SUDAM), e foi delimitada de acordo como Art. 2o da Lei Complementar n. 124, de 03.01.2007. Possui uma superfície aproximada de $5.015 .067,75 \mathrm{~km}^{2}$, correspondente a cerca de $58,9 \%$ do território brasileiro. É composta por 8 estados brasileiros em sua totalidade e por parte do estado do Maranhão. (IBGE, 2021). 
Figura 1 - Mapa de localização da Amazônia Legal.

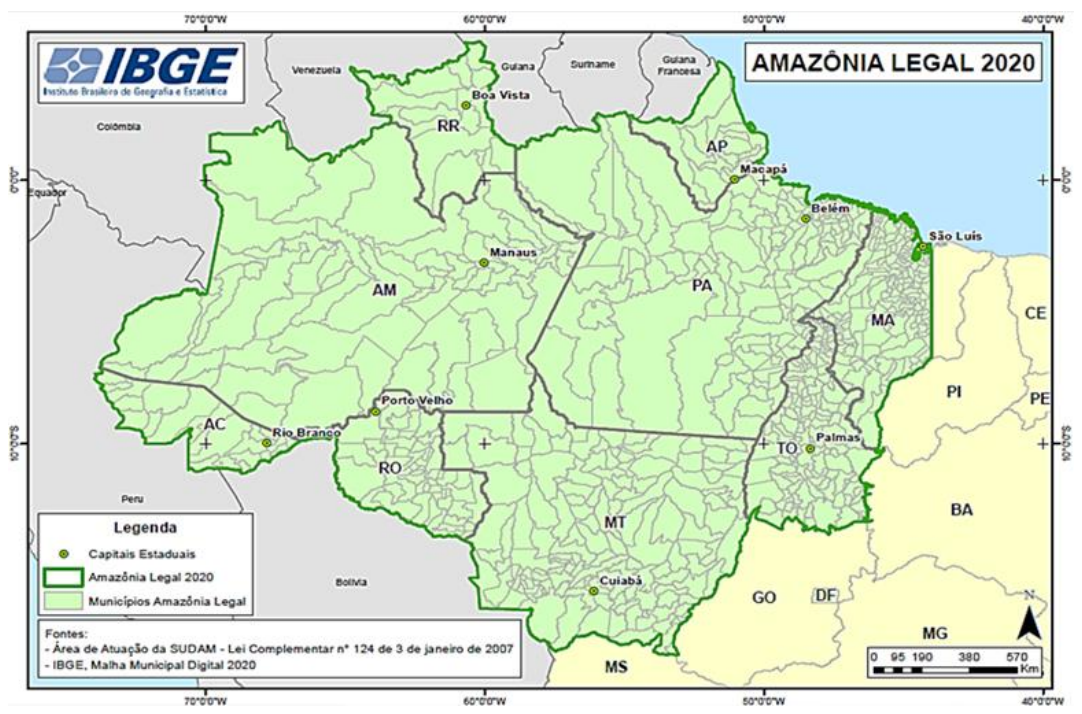

Fonte: IBGE (2021).

\subsection{Tipo de Estudo}

Para a operacionalização da catalogação das TS acerca do tema delimitado pelo objetivo desta pesquisa, os procedimentos empregados estão classificados como Pesquisa Bibliográfica, devido as informações coletadas terem sido encontradas em materiais já elaborados (Gil, 2008). Quanto ao objetivo da pesquisa, ela é considerada como exploratória, Gil (2017), detalha este tipo de pesquisa como um modelo bastante flexível e que possibilita uma vasta amplitude dos aspectos a serem considerados acerca do tema estudado, possibilitando novos conhecimentos e hipóteses sobre temas pouco explorados, fornecendo assim base para novas pesquisas.

\subsection{Etapas da Pesquisa}

Para o cumprimento dos objetivos da pesquisa, foram realizadas 6 etapas (Figura 2).

Figura 2 - Fluxograma das Etapas da Pesquisa.

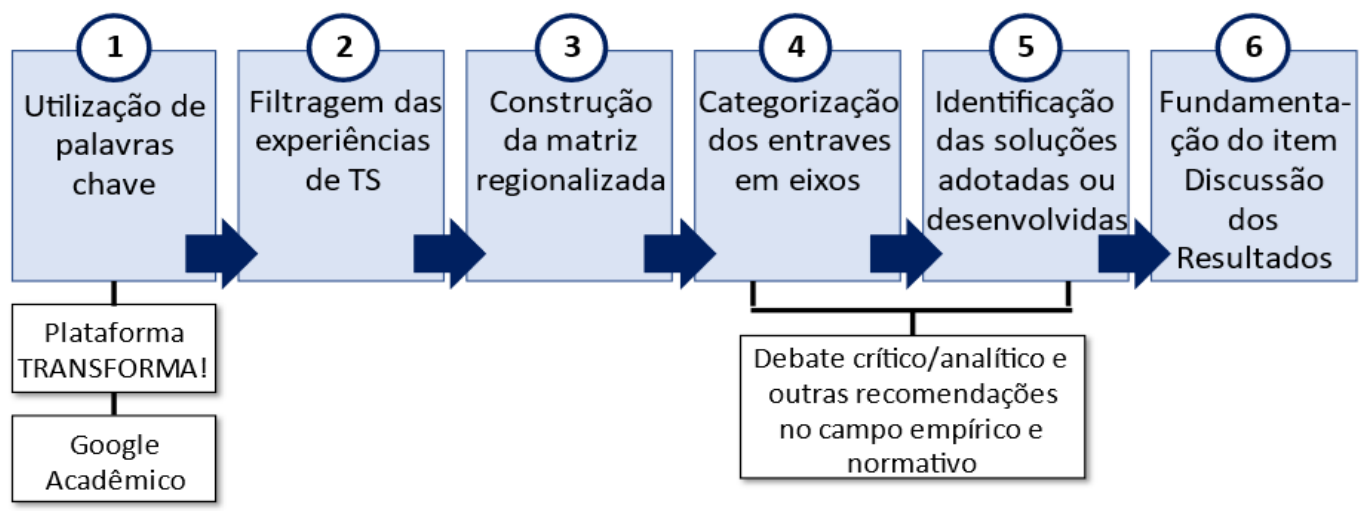

Fonte: Autores (2022).

A localização das experiências de TS nas plataformas de pesquisa, foi realizada por meio da utilização de palavraschave que pautassem o foco desta pesquisa (tecnologias sociais), a área de estudo relacionada (resíduos sólidos) e a parcela da sociedade envolvida (cooperativas e associações de catadores de materiais recicláveis). Os bancos de dados escolhidos para 
levantamento foram dois: o Transforma!, da Fundação Banco do Brasil (FBB) e o Google Acadêmico (Google Scholar).

$\mathrm{Na}$ base de dados Transforma!, as informações encontravam-se de maneira mais aberta, fora do formato de publicação acadêmica. As experiências que atendessem aos critérios de relevância para esta pesquisa começaram a ser catalogadas. Quanto ao Google Acadêmico, fez-se uma leitura dos resumos e um levantamento preliminar dos artigos encontrados. Os trabalhos considerados pertinentes para esta investigação foram adquiridos na íntegra, onde a leitura integral e analítica foi realizada.

Após essa primeira etapa de pesquisa nas plataformas selecionadas, foi realizada a filtragem das experiências de TS encontradas (Etapa 2), suas ideias-chave foram identificadas, e seus resultados organizados e sintetizados para a realização da catalogação e descrição das características de cada TS, possibilitando a construção da matriz regionalizada (Etapa 3) que foi formulada com a estrutura demonstrada na Figura 3.

Figura 3 - Estrutura da Matriz Regionalizada.

\begin{tabular}{|c|l|l|}
\hline \multicolumn{3}{|c|}{ Região } \\
\hline 1 & Cooperativa/Associação: & Município: \\
\cline { 2 - 3 } & UF: & \\
\hline $\begin{array}{c}\text { Objetivo } \\
\text { da TS }\end{array}$ & \\
\hline $\begin{array}{c}\text { Descrição } \\
\text { da TS }\end{array}$ & \\
\hline $\begin{array}{c}\text { Principais } \\
\text { Entraves }\end{array}$ & \\
\hline $\begin{array}{c}\text { Principais } \\
\text { Avanços }\end{array}$ & \\
\hline
\end{tabular}

Fonte: Autores (2022).

Com as informações devidamente organizadas na matriz regionalizada, foi possível a identificação dos principais entraves enfrentados pelas cooperativas e associações antes ou durantes o desenvolvimento das TS. Assim, com base no debate crítico/analítico e outras recomendações no campo empírico e normativo vistos durante a revisão da literatura, os entraves identificados foram categorizados em 4 eixos: econômico, ambiental, institucional e social (Etapa 4). A categorização dos entraves por eixo, possibilitou em seguida a apresentação das soluções adotadas ou desenvolvidas para eles (Etapa 5).

$\mathrm{Na}$ sexta e última etapa do trabalho, a pesquisa das TS, a construção da matriz regionalizada, a categorização dos entraves, a identificação das soluções adotadas/desenvolvidas, possibilitaram a fundamentação necessária para a discussão dos resultados identificados, destacando-se a situação observada na Amazônia Brasileira em relação ao desenvolvimento de TS no âmbito das cooperativas e associações de catadores de materiais recicláveis e o contexto histórico, político e social da região.

\section{Resultados}

\subsection{Construção da Matriz Analítica Regionalizada das Experiências Brasileiras de TS no Âmbito das Cooperativas e} Associações de Catadores de Materiais Recicláveis

Após o levantamento das experiências, ocorreu a etapa de extração de dados, o que permitiu exame das TS selecionadas para a compreensão dos resultados. A seguir tem-se, no Quadro 1, a matriz analítica regionalizada das experiências brasileiras de TS. Na matriz estão destacadas as cooperativas/associações, o objetivo de cada TS, a sua descrição, e os principais entraves e avanços que foram observados antes e durante a aplicação da tecnologia. 
Quadro 1 - Matriz regionalizada das experiências brasileiras de TS no âmbito das cooperativas e associações de catadores de materiais recicláveis.

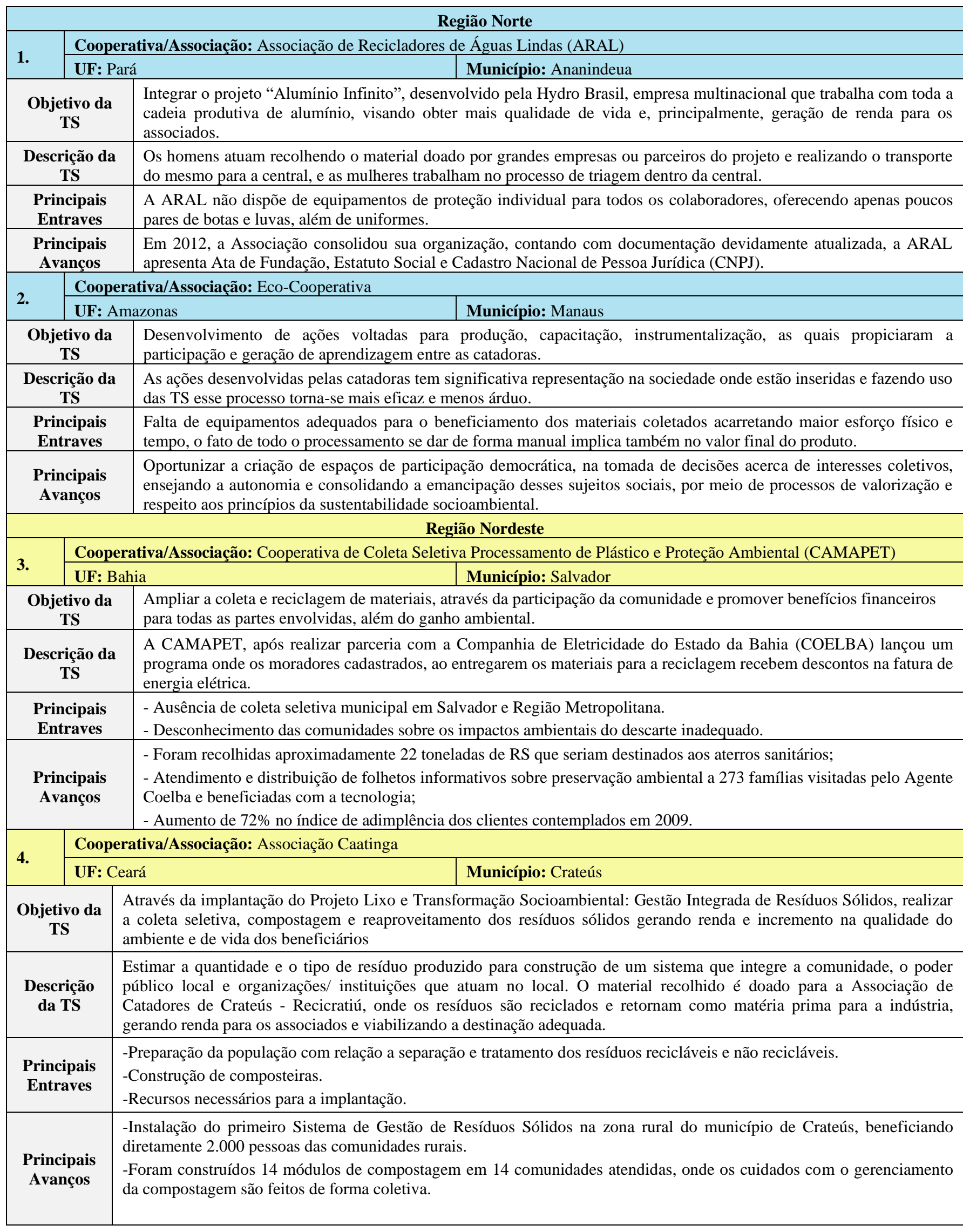




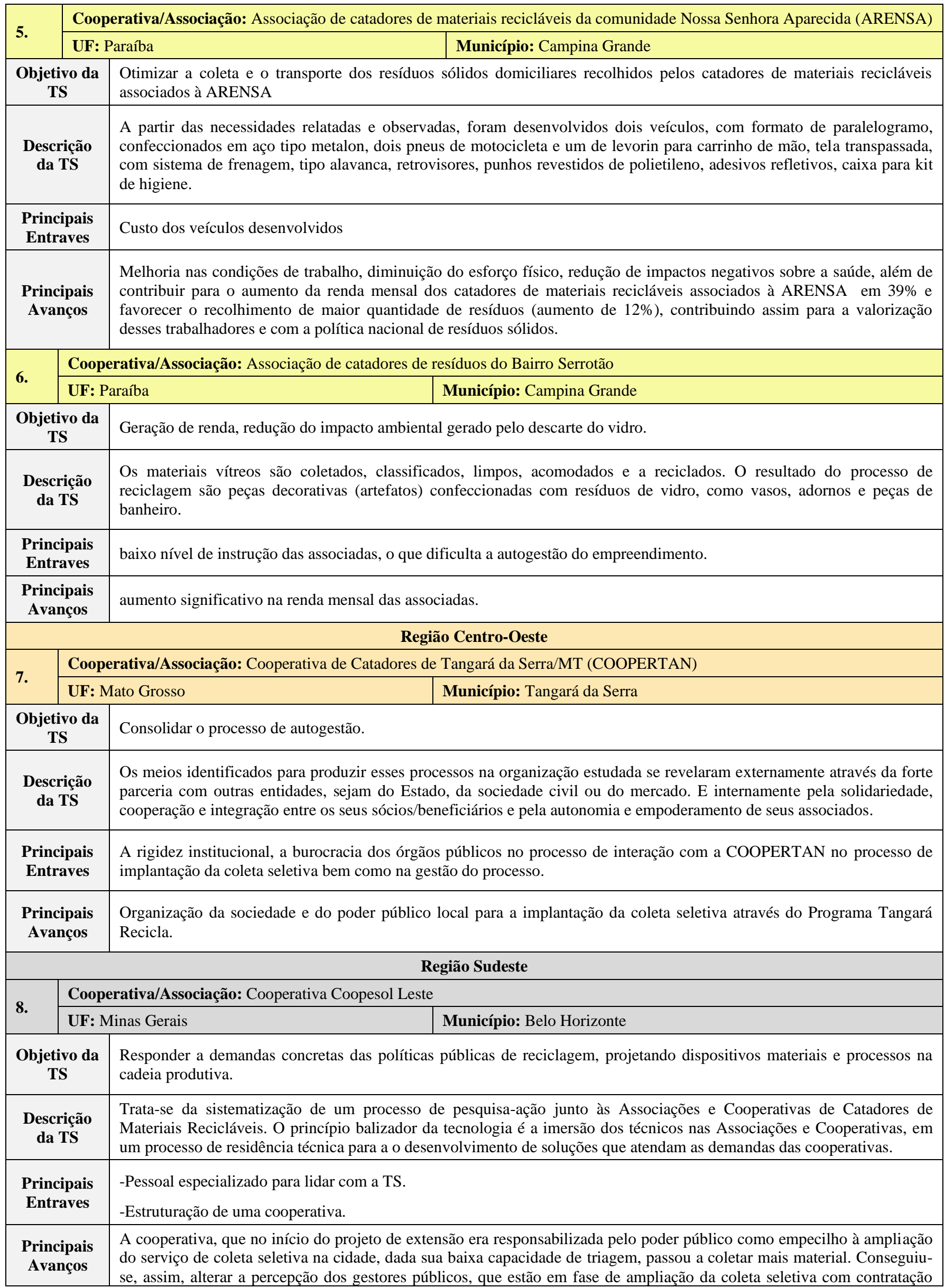




\begin{tabular}{|c|c|c|c|}
\hline & & \multicolumn{2}{|c|}{ a realização dos serviços de coleta. } \\
\hline \multirow{2}{*}{9.} & \multicolumn{3}{|c|}{ Cooperativa/Associação: Cooperativa de Catadores Autônomos de Uberaba (COOPERU) } \\
\hline & \multicolumn{2}{|c|}{ UF: Minas Gerais } & Município: Uberaba \\
\hline \multicolumn{2}{|c|}{$\begin{array}{l}\text { Objetivo da } \\
\text { TS }\end{array}$} & \multicolumn{2}{|c|}{$\begin{array}{l}\text { Promover a mobilização social continuada desenvolvida em parceria com a comunidade, visando à implementação de } \\
\text { práticas socialmente responsáveis a partir de duas vertentes: a educação ambiental para a efetivação da coleta seletiva } \\
\text { mobilização para a destinação correta de resíduos na cidade e a mobilização local de recursos para o Fundo Municipal da } \\
\text { Criança e do Adolescente de Uberaba - FUMDICAU. }\end{array}$} \\
\hline \multicolumn{2}{|c|}{$\begin{array}{l}\text { Descrição } \\
\text { da TS }\end{array}$} & \multicolumn{2}{|c|}{$\begin{array}{l}\text { Promover a articulação em rede e o fortalecimento do trabalho intersetorial em prol do desenvolvimento sustentável da } \\
\text { comunidade local. A Coleta dos materiais recicláveis é feita pela (COOPERU), que se beneficia com o material coletado, } \\
\text { aumentando a geração de renda dos catadores. }\end{array}$} \\
\hline \multicolumn{2}{|c|}{$\begin{array}{l}\text { Principais } \\
\text { Entraves }\end{array}$} & \multicolumn{2}{|c|}{$\begin{array}{l}\text {-A inexistência de um sistema estruturado de coleta seletiva para o descarte correto de resíduos. } \\
\text {-Influenciar o protagonismo de crianças e adolescentes através da Gincana Verde. } \\
\text {-Sensibilização da comunidade para a coleta seletiva. }\end{array}$} \\
\hline \multicolumn{2}{|c|}{$\begin{array}{l}\text { Principais } \\
\text { Avanços }\end{array}$} & \multicolumn{2}{|c|}{$\begin{array}{l}\text {-A destinação correta de mais de } 70000 \text { lâmpadas, } 31738 \mathrm{k} \\
\text { além de mais de } 1000 \mathrm{~kg} \text { de pilhas e baterias. } \\
\text { - Aumento de renda dos cooperados. }\end{array}$} \\
\hline \multicolumn{4}{|r|}{ Região Sul } \\
\hline \multirow{2}{*}{10.} & \multicolumn{3}{|c|}{ Cooperativa/Associação: Centro de Estudos e Promoção da Agricultura de Grupo (CEPAGRO) } \\
\hline & \multicolumn{2}{|c|}{ UF: Santa Catarina } & Município: Flori \\
\hline \multicolumn{2}{|c|}{$\begin{array}{l}\text { Objetivo da } \\
\text { TS }\end{array}$} & \multicolumn{2}{|c|}{$\begin{array}{l}\text { Através do Projeto Revolução Baldinhos (PRB), que é uma iniciativa de gestão comunitária de resíduos orgânicos e } \\
\text { agricultura urbana, sensibilizar as famílias para a reciclagem das sobras de comida e as transformar em composto } \\
\text { orgânico, disseminando o plantio como promoção da saúde e alimentação saudável. }\end{array}$} \\
\hline \multicolumn{2}{|c|}{$\begin{array}{l}\text { Descrição } \\
\text { da TS }\end{array}$} & \multicolumn{2}{|c|}{$\begin{array}{l}\text { O projeto se organiza em três eixos: 1) mobilização e sensibilização das comunidades que vivem em áreas periféricas de } \\
\text { Florianópolis; 2) execução; 3) incidência política. Busca que o valor pago pela prefeitura para se enterrar o "lixo", seja } \\
\text { repassado ao grupo comunitário para as ações de reciclagem, garantindo a autonomia e renda aos envolvidos para que } \\
\text { essas ações possam ser reaplicadas. }\end{array}$} \\
\hline \multicolumn{2}{|c|}{$\begin{array}{l}\text { Principais } \\
\text { Entraves }\end{array}$} & \multicolumn{2}{|c|}{$\begin{array}{l}\text { - Formação de uma cooperativa legalizada. } \\
\text { - Recursos necessários para o processo de compostagem. } \\
\text {-Capacitação das pessoas para o desenvolvimento da técnica de compostagem termofílica. }\end{array}$} \\
\hline \multicolumn{2}{|c|}{$\begin{array}{l}\text { Principais } \\
\text { Avanços }\end{array}$} & \multicolumn{2}{|c|}{$\begin{array}{l}\text { Benefício a } 200 \text { famílias com a coleta dos resíduos orgânicos (aproximadamente } 750 \text { pessoas), } 06 \text { unidades escolares, } \\
\text { aproximadamente } 800 \text { pessoas entre crianças e educadores e três ONGs, formadas por associações comunitárias e } \\
\text { entidades ligadas às igrejas. Somados, são em torno de } 1550 \text { pessoas beneficiadas diretamente. Os resultados estão na } \\
\text { diminuição dos ratos com a coleta do resíduo orgânico e a produção do composto orgânico. Cerca de } 500 \text { toneladas de } \\
\text { resíduos orgânicos já foram recicladas desde o início do PRB. }\end{array}$} \\
\hline \multirow{2}{*}{11.} & \multicolumn{3}{|c|}{ Cooperativa/Associação: Cooperativa dos Agentes Ambientais de Foz do Iguaçu } \\
\hline & \multicolumn{2}{|c|}{ UF: Paraná } & Município: Foz do Iguaçu \\
\hline \multicolumn{2}{|c|}{$\begin{array}{l}\text { Objetivo da } \\
\text { TS }\end{array}$} & \multicolumn{2}{|c|}{$\begin{array}{l}\text { Melhorar as condições de trabalho dos catadores através de um veículo de tração elétrica, não tripulado, que introduz o } \\
\text { uso da energia elétrica nos meios de produção dessa classe de trabalhadores. Assim, minimizar o esforço físico na } \\
\text { movimentação dos materiais recicláveis coletado, maximizar a produtividade e aumentar a renda, com a consequente } \\
\text { melhoria na qualidade de vida dos catadores e de seus familiares. }\end{array}$} \\
\hline \multicolumn{2}{|c|}{$\begin{array}{l}\text { Descrição } \\
\text { da TS }\end{array}$} & \multicolumn{2}{|c|}{$\begin{array}{l}\text { O Veículo Elétrico para Catadores (VEC) é uma ferramenta que tem por objetivo o transporte de materiais recicláveis que } \\
\text { introduz o uso da energia elétrica nas atividades do catador. É movimentado por um motor elétrico, sendo livre de emissão } \\
\text { de poluentes. Transporta } 300 \mathrm{~kg} \text { à velocidade de até } 6 \mathrm{~km} / \mathrm{h} \text { e tem autonomia de } 25 \mathrm{~km} \text {. A TS foi desenvolvida pela } \\
\text { Fundação Parque Tecnológico Itaipu }\end{array}$} \\
\hline \multicolumn{2}{|c|}{$\begin{array}{l}\text { Principais } \\
\text { Entraves }\end{array}$} & \multicolumn{2}{|c|}{$\begin{array}{l}\text { Necessidade de uma oficina mecânica ou serralheria para montagem do VEC. } \\
\text { Montador capacitado em usinagem e solda para realizar o trabalho de montagem. }\end{array}$} \\
\hline \multicolumn{2}{|c|}{$\begin{array}{l}\text { Principais } \\
\text { Avanços }\end{array}$} & \multicolumn{2}{|c|}{$\begin{array}{l}\text {-Aumento significativo de produtividade, pois pode ser transportado no } \mathrm{V} \\
\text {-Introdução dos catadores à era da energia elétrica como insumo da produ }\end{array}$} \\
\hline 12 & Coo & rativa/Assoc & grama Oficina Educativa \\
\hline 12. & & Catarina & \\
\hline & & $\begin{array}{l}\text { Coletar rec } \\
\text { Programa } \\
\end{array}$ & $\begin{array}{l}\text { ar recursos e atender adolescentes em situação de risco. O Verde Vida } \\
\text { n fins não econômicos. }\end{array}$ \\
\hline & & oportun & $\begin{array}{l}\text { da atuação de } 14 \text { oficinas oferecidas no contra turno da escola que } \\
\text { ais, esportivas, de lazer, e de reforço escolar, além de informações e } \\
\text { lho. }\end{array}$ \\
\hline & & Alguns equ & inhões, camionetes, prensas, prensa horizontal, triturador, esteiras, \\
\hline
\end{tabular}




\begin{tabular}{|c|c|c|c|}
\hline \multirow{3}{*}{\multicolumn{2}{|c|}{$\begin{array}{l}\text { Entraves } \\
\text { Principais } \\
\text { Avanços }\end{array}$}} & \multirow{3}{*}{\multicolumn{2}{|c|}{$\begin{array}{l}\text { empilhadeira, camionetes Strada, aparelho de solda, ferramentas, bebedouros, para atender a parte produtiva. } \\
\text {-No decorrer dos anos já passaram mais de } 5.000 \text { jovens, a maioria dos quais foram para o mercado de trabalho formal, } \\
\text { alguns fizeram faculdade } \\
\text {-A parte da produção processa (coleta, separação e venda) a média de } 250 \text { toneladas/mês. }\end{array}$}} \\
\hline & & & \\
\hline & & & \\
\hline \multirow[t]{2}{*}{13.} & \multicolumn{3}{|r|}{ Trabalhadores e Prestadores de Serviços na Reciclagem de Resíduos Sólidos de } \\
\hline & \multicolumn{2}{|c|}{ UF: Paraná } & Município: Umuarama \\
\hline \multicolumn{2}{|c|}{\begin{tabular}{l|} 
Objetivo da \\
TS
\end{tabular}} & \multicolumn{2}{|c|}{$\begin{array}{l}\text { objetivo incentivar a separação dos resíduos sólidos, a coleta seletiva e a produção rural, } \\
\text { abientais, preservar as águas da APA, gerar renda e melhorar a qualidade de vida. }\end{array}$} \\
\hline \multicolumn{2}{|c|}{$\begin{array}{l}\text { Descrição } \\
\text { da TS }\end{array}$} & \multicolumn{2}{|c|}{$\begin{array}{l}\text { O material coletado é destinado para a COOPERUMA-Cooperativa dos Trabalhadores e Prestadores de Serviços na } \\
\text { Reciclagem de Resíduos Sólidos de Umuarama que recebe o material, faz a triagem, separação, prensagem e venda do } \\
\text { material, gerando renda para as } 35 \text { famílias cooperadas. }\end{array}$} \\
\hline \multicolumn{2}{|c|}{$\begin{array}{l}\text { Principais } \\
\text { Entraves }\end{array}$} & \multicolumn{2}{|r|}{ ndida pelo projeto e acesso a uma qualidade de vida adequada. } \\
\hline \multicolumn{2}{|c|}{$\begin{array}{l}\text { Principais } \\
\text { Avanços }\end{array}$} & \multicolumn{2}{|c|}{$\begin{array}{l}\text {-Em } 2014 \text { foram coletadas } 275 \text { toneladas de resíduos sólidos, foram atendidas } 527 \text { famílias e foram disponibilizados para a } \\
\text { população participante do projeto aproximadamente } 110 \text { toneladas de alimentos. } \\
\text {-Melhoria na renda dos cooperados da COOPERUMA- Cooperativa dos Trabalhadores e Prestadores de Serviços na } \\
\text { Reciclagem de Resíduos Sólidos de Umuarama. } \\
\text {-Redução na proliferação de vetores causadores de doenças }\end{array}$} \\
\hline \multirow{2}{*}{14.} & \multicolumn{3}{|c|}{ Cooperativa/Associação: Cooperativa de catadores de materiais reciclados da cidade de Toledo } \\
\hline & \multicolumn{2}{|c|}{ UF: Paraná } & Município: Toledo \\
\hline \multicolumn{2}{|c|}{$\begin{array}{l}\text { Objetivo } \\
\text { da TS }\end{array}$} & \multicolumn{2}{|c|}{$\begin{array}{l}\text { O Projeto Reuso De Resíduos Vítreos De Aterros Sanitários: Meio Ambiente E Renda, tem por objetivo o } \\
\text { desenvolvimento de soluções locais a respeito da reciclagem do vidro. }\end{array}$} \\
\hline \multicolumn{2}{|c|}{$\begin{array}{l}\text { Descrição } \\
\text { da TS }\end{array}$} & \multicolumn{2}{|c|}{$\begin{array}{l}\text {-O projeto desenvolvido busca soluções para utilização do vidro encontrado em aterros municipais que consigam gerar } \\
\text { renda à cooperativa com a comercialização do vidro na forma de pó para aplicações na construção civil. }\end{array}$} \\
\hline \multicolumn{2}{|c|}{$\begin{array}{l}\text { Principais } \\
\text { Entraves }\end{array}$} & \multicolumn{2}{|c|}{$\begin{array}{l}\text { atividade com baixa remuneração para cooperativas/catadores de materiais reciclados, } \\
\text { difícil destinação final. } \\
\text { em diversas composições dificulta os processos de reciclagem, principalmente por } \\
\text { le material. }\end{array}$} \\
\hline \multicolumn{2}{|c|}{$\begin{array}{l}\text { Principais } \\
\text { Avanços }\end{array}$} & \multicolumn{2}{|c|}{$\begin{array}{l}\text {-A cooperativa de catadores de materiais reciclados da cidade de Toledo já processa o vidro e comercializa o mesmo na } \\
\text { forma de pó com separação de faixas. } \\
\text {-O projeto ajuda a cooperativa com a comercialização do pó de vidro e aplica localmente o material em obras reduzindo a } \\
\text { necessidade de areia que é recurso natural finito. }\end{array}$} \\
\hline \multirow[t]{2}{*}{15.} & \multicolumn{3}{|c|}{$\begin{array}{l}\text { Cooperativa/Associação: Associação de Catadores de Materiais Recicláveis e/ou Reaproveitáveis de Santa Terezinha de Itaipu } \\
\text { (ACARESTI) }\end{array}$} \\
\hline & \multicolumn{2}{|c|}{ UF: Paraná } & \\
\hline \multicolumn{2}{|c|}{$\begin{array}{l}\text { Objetivo } \\
\text { da TS }\end{array}$} & \multicolumn{2}{|r|}{$\begin{array}{l}\text { Ses. O Programa de Coleta Seletiva, nem tudo é lixo foi criado em 2004, esta } \\
\text { Santa Terezinha de Itaipu foi reestruturada em } 2014 .\end{array}$} \\
\hline \multicolumn{2}{|c|}{$\begin{array}{l}\text { Descrição } \\
\text { da TS }\end{array}$} & \multicolumn{2}{|c|}{$\begin{array}{l}\text { Proporcionar a venda dos materiais separados e prensados, e assim, dividir entre os associados conforme os dias } \\
\text { trabalhados. Hoje a Associação de Catadores de Materiais Recicláveis e/ou Reaproveitáveis de Santa Terezinha de Itaipu - } \\
\text { ACARESTI é constituída por } 40 \text { catadores que trabalham no centro de triagem da ACARESTI no formato de associação. }\end{array}$} \\
\hline \multicolumn{2}{|c|}{$\begin{array}{l}\text { Principais } \\
\text { Entraves }\end{array}$} & \multicolumn{2}{|c|}{$\begin{array}{l}\text {-Divulgação do programa de forma efetiva, seja na área urbana ou rural do município. } \\
\text {-Distribuição dos calendários educativos. } \\
\text {-Parceria da prefeitura com os catadores. }\end{array}$} \\
\hline \multicolumn{2}{|c|}{$\begin{array}{l}\text { Principais } \\
\text { Avanços }\end{array}$} & \multicolumn{2}{|c|}{$\begin{array}{l}\text {-Antes da reestruturação do programa os catadores coletavam cerca de } 30 \text { toneladas de materiais ao mês, já no de } 2014 \text { a } \\
\text { média passou para } 110 \text { toneladas/mês, chegando ao índice de } 85 \% \text { da participação da população na separação dos } \\
\text { materiais recicláveis gerados no município. } \\
\text {-A renda média dos catadores antes do projeto era de } 450,00 \text { reais, e passou para } 1.300,00 \text { por catador ao mês. Além disso } \\
\text { aumentou em } 40 \% \text { a vida útil do Aterro Sanitário. }\end{array}$} \\
\hline 16 & & & \\
\hline 10. & UF: 1 & do Sul & pio: Ijuí \\
\hline & & $\mathrm{scl}$ & ocm \\
\hline & & & e empoderamento do grupo e bus \\
\hline
\end{tabular}




\begin{tabular}{|c|l|l|}
\hline $\begin{array}{c}\text { Principais } \\
\text { Entraves }\end{array}$ & Alto índice de analfabetismo entre os associados. \\
\hline $\begin{array}{c}\text { Principais } \\
\text { Avanços }\end{array}$ & Empoderamento dos associados, maior união entre os mesmos em busca de preços justos por seus materiais. \\
\hline \multirow{2}{*}{ 17. } & Cooperativa/Associação: Cooperativa de Recicladores de Dois Irmãos \\
\cline { 2 - 4 } & UF: Rio Grande do Sul & Município: Dois Irmãos \\
\hline $\begin{array}{c}\text { Objetivo da } \\
\text { TS }\end{array}$ & Otimização do processo e aumento da capacidade de produção. \\
\hline $\begin{array}{c}\text { Descrição } \\
\text { da TS }\end{array}$ & O beneficiamento do plástico é realizado basicamente em duas bateladas separadas: o processamento do material rígido \\
\hline $\begin{array}{c}\text { Principais } \\
\text { Entraves }\end{array}$ & Falta de parcerias com as prefeituras vizinhas, para aumentar o recebimento de materiais \\
\hline $\begin{array}{c}\text { Principais } \\
\text { Avanços }\end{array}$ & $\begin{array}{l}\text { Os impactos econômicos da Tecnologia Social adotada relacionam-se diretamente com a capacidade do empreendimento } \\
\text { de formar preço frente ao restante do mercado. }\end{array}$ \\
\hline
\end{tabular}

Fonte: TRANSFORMA! (2021); Santos e Zamora (2013); Costa (2015); Ribeiro e da Silva (2015); De Souza et al. (2015); Farias et al. (2015); Sguarezi et al. (2018); Autores (2022).

A partir das investigações, identificou-se que 17 experiências de TS foram desenvolvidas por, ou em conjunto com as cooperativas/associações. As TS catalogadas na matriz, possuem objetivos diversificados e que englobam múltiplos propósitos entre os quais estão: a implantação ou ampliação de coleta seletiva e reciclagem de materiais; gestão integrada de resíduos sólidos; transformação socioambiental; reaproveitamento dos RS; educação ambiental; redução de impactos ambientais; desenvolvimento de soluções locais; aumento do tempo de vida de aterros sanitários; otimização de processos de triagem, tratamento e transporte de RS; consolidação do cooperativismo e entre todos os objetivos identificados, os que mais estão presentes é o desígnio em aumentar a renda e qualidade de vida dos trabalhadores envolvidos.

Os principais entraves que as TS analisadas tiveram que enfrentar, após identificados na matriz (Quadro 1), foram categorizados em 4 eixos: econômico, ambiental, institucional e social. O primeiro abrange a falta de Equipamentos de Proteção Individual (EPI) para os trabalhadores, a falta de infraestrutura (maquinário especializado, veículos, local adequado), insuficiência de recursos para a operacionalização das TS, assim também como os baixos valores pagos por alguns materiais coletados; o segundo compreende a inexistência ou ineficiência da coleta seletiva e a baixa participação da população afetada pela TS; o terceiro engloba as questões das dificuldades com a burocracia, e para a formalização das cooperativas, além da carência de parcerias com os setores públicos ou privados; e por fim, o quarto eixo tange a problemática da falta de capacitação entre os trabalhadores, altos índices de analfabetismo e a vulnerabilidade socioeconômica a que estes trabalhadores estão expostos. A distribuição dos entraves que compõem os eixos definidos, e as respectivas porcentagens das cooperativas/associações que os relataram, é apresentada na Tabela 1. Observando que o total da porcentagem ultrapassa os $100 \%$ devido ao fato de um mesmo entrave ter sido identificado em mais de uma cooperativa/associação.

Tabela 1 - Categorização dos entraves identificados por eixo e suas porcentagens.

\begin{tabular}{|c|c|c|}
\hline EIXO & ENTRAVES IDENTIFICADOS & $\begin{array}{c}\text { PORCENTAGEM DE } \\
\text { COOPERATIVAS/ASSOCIAÇÕES } \\
\text { AFETADAS POR ENTRAVE } \\
\end{array}$ \\
\hline \multirow{4}{*}{ 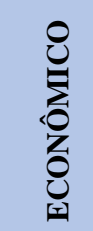 } & Falta de EPI & $5,9 \%$ \\
\hline & Falta de infraestrutra & $17,6 \%$ \\
\hline & Insuficiencia de recursos para a operacionalização da TS & $17,6 \%$ \\
\hline & Baixos valores pagos por alguns materiais coletados & $5,9 \%$ \\
\hline
\end{tabular}


Research, Society and Development, v. 11, n. 2, e51311226003, 2022

(CC BY 4.0) | ISSN 2525-3409 | DOI: http://dx.doi.org/10.33448/rsd-v11i2.26003

\begin{tabular}{l|l|c}
\hline & Inexistência ou ineficiência da coleta seletiva & $17,6 \%$ \\
\cline { 2 - 3 } & Baixa participação da população nas ações & $17,6 \%$ \\
\hline & Excesso de burocracia dos órgãos públicos para a implantação de ações & $5,9 \%$ \\
\cline { 2 - 3 } & Dificuldade para a formalização da cooperativa & $11,8 \%$ \\
\cline { 2 - 3 } & Falta de parcerias públicas ou privadas & $11,8 \%$ \\
\hline & Falta de capacitação entre os trabalhadores & $29,4 \%$ \\
\cline { 2 - 3 } & Vulnerabilidade socioeconômica & $5,9 \%$ \\
\hline
\end{tabular}

Fonte: Autores (2022).

Com relação aos locais de implantação das TS, observou-se pelo Quadro 2, que houve um total de 10 estados, a saber: Amazonas, Bahia, Ceará, Mato Grosso, Minas Gerais, Pará, Paraíba, Paraná, Rio Grande do Sul e Santa Catarina. De posse destas informações, foi elaborada a Figura 4, que compreende um diagrama com as porcentagens referentes a somatória dos entraves que compõem cada eixo, a localização regional das cooperativas/associações que enfrentaram os entraves e as soluções adotadas/desenvolvidas por eixo. Como anteriormente, ressalta-se que a somatória das porcentagens ultrapassa os $100 \%$ por um mesmo entrave ter sido identificado em mais de uma cooperativa/associação. 
Figura 4 - Diagrama coma regionalização dos eixos e as respectivas soluções adotadas/desenvolvidas.

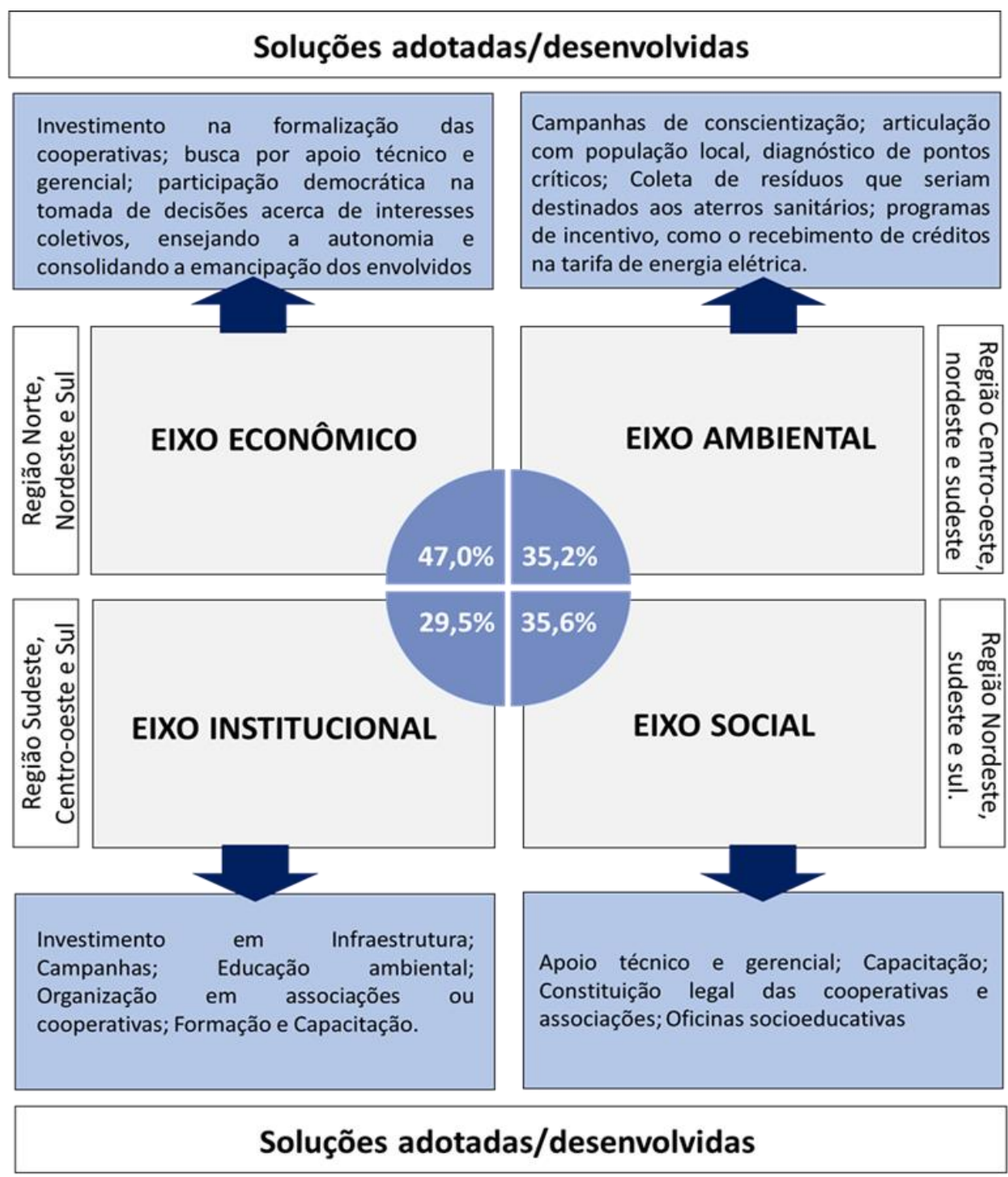

Fonte: Autores (2022).

De forma geral, os principais avanços com relação as experiências relatadas nas cooperativas/associações foram: a formalização de cooperativas; o empoderamento, valorização e capacitação dos trabalhadores envolvidos; desenvolvimento de programas de compostagem; mobilização da comunidade; otimização dos processos de coleta e reciclagem; aumento de produtividade; implantação/ampliação da coleta seletiva; correta destinação dos resíduos; redução na proliferação de vetores causadores de doenças; melhoria nas condições de trabalho; acesso da população a alimentação adequada; melhoria de qualidade de vida e significativo aumento da renda dos cooperados em quase todas as experiências.

Durante o levantamento de TS nos bancos de dados selecionados, além das 17 TS desenvolvidas diretamente por e/ou para as cooperativas e associações, descritas no Quadro 1, foram identificadas na plataforma TRANSFORMA!, 12 TS que incluem ações e projetos organizados por iniciativas públicas ou privadas, e que apesar de não terem sido desenvolvidos diretamente nas, ou em conjunto com as cooperativas e associações, beneficiam indiretamente cooperados e associados, pois empoderam e fortalecem as populações envolvidas, estimulando assim o fortalecimento de princípios como o associativismo, cooperativismo, da economia solidária e da autossustentação financeira, além de envolverem a utilização de materiais recicláveis. Dessa forma considerou-se de extrema relevância que essas TS também fossem apresentadas de maneira regionalizada nesta pesquisa. No Quadro 2 pode-se observar as principais informações de cada experiência. 
Quadro 2 - Matriz regionalizada das experiências brasileiras de TS que beneficiam indiretamente os cooperados e associados.

\begin{tabular}{|c|c|c|c|}
\hline \multicolumn{4}{|r|}{ Região Nordeste } \\
\hline \multirow{2}{*}{1.} & \multicolumn{3}{|c|}{ Instituição: Universidade Federal da Bahia (UFBA) } \\
\hline & \multicolumn{2}{|c|}{ UF: Bahia } & Município: Salvador \\
\hline \multicolumn{2}{|c|}{$\begin{array}{l}\text { Objetivo } \\
\text { da TS }\end{array}$} & \multicolumn{2}{|c|}{$\begin{array}{l}\text { A TS de produção de dispositivos acústicos com fibras naturais tem por objetivo implementar as tecnologias utilizadas na } \\
\text { fabricação destes, a partir de resíduos naturais e colaborar para o desenvolvimento sustentável das comunidades } \\
\text { quilombolas e ribeirinhas }\end{array}$} \\
\hline \multicolumn{2}{|c|}{$\begin{array}{l}\text { Descrição } \\
\text { da TS }\end{array}$} & \multicolumn{2}{|c|}{$\begin{array}{l}\text { Capacitar, certificar os artefatos acústicos e as persianas artesanais, e por fim, elaborar Diagnósticos ambientais, de saúde } \\
\text { da população e resgaste da cultura local (valores, tradições, danças, brincadeiras). }\end{array}$} \\
\hline \multicolumn{2}{|c|}{$\begin{array}{l}\text { Principais } \\
\text { Entraves }\end{array}$} & \multicolumn{2}{|c|}{$\begin{array}{l}\text {-Necessidade de equipamentos, como, triturador, liquidificador, amassadeira, prensa aquecida, moldes de ferro, painéis } \\
\text { acústicos, suporte de tábua de pinho, fibras de dendê ou piaçava e linha de retinida- rolos }\end{array}$} \\
\hline \multicolumn{2}{|c|}{$\begin{array}{l}\text { Principais } \\
\text { Avanços }\end{array}$} & \multicolumn{2}{|c|}{$\begin{array}{l}\text { Melhoria da qualidade de vida da população em estudo, com relação a otimização da preservação ambiental, mediante o } \\
\text { aproveitamento dos resíduos gerados nas atividades desenvolvidas pela comunidade, reduzindo assim o volume de resíduos } \\
\text { queimados ou descartados indevidamente. }\end{array}$} \\
\hline \multirow{2}{*}{2.} & \multicolumn{3}{|c|}{ Instituição: Grupo de interesse ambiental } \\
\hline & \multicolumn{2}{|c|}{ UF: Ceará } & Município: Fortaleza \\
\hline \multicolumn{2}{|c|}{$\begin{array}{l}\text { Objetivo da } \\
\text { TS }\end{array}$} & \multicolumn{2}{|c|}{$\begin{array}{l}\text { O Projeto Energia Empreendedora tem por objetivo promover a formação e/ou capacitação profissional de homens e } \\
\text { mulheres em situação de vulnerabilidade social, residentes em bairros de baixo IDH da cidade de Fortaleza/CE. }\end{array}$} \\
\hline \multicolumn{2}{|c|}{$\begin{array}{l}\text { Descrição } \\
\text { da TS }\end{array}$} & \multicolumn{2}{|c|}{$\begin{array}{l}\text { Visa a oportunidades de negócios e geração de renda por meio da transformação de resíduos sólidos - como lonas, sobras } \\
\text { de tecidos, papéis, plásticos - colocando estes em um novo ciclo de vida. }\end{array}$} \\
\hline \multicolumn{2}{|c|}{$\begin{array}{l}\text { Principais } \\
\text { Entraves }\end{array}$} & \multicolumn{2}{|c|}{$\begin{array}{l}\text { - Mobilização e divulgação. } \\
\text { - Formação técnica- teórica } \\
\text { - Formação técnica- prática }\end{array}$} \\
\hline \multicolumn{2}{|c|}{$\begin{array}{l}\text { Principais } \\
\text { Avanços }\end{array}$} & \multicolumn{2}{|c|}{$\begin{array}{l}\text { - Capacitação das pessoas e possiblidade de novo rumo profissior } \\
\text { - Empresas privadas/ públicas e pessoas fazendo o descarte } \\
\text { ecológicos e; inserção dos produtos ecológicos no mercado de ev } \\
\text { - O total de RS recebidos foi } 22.773 \mathrm{~kg} \text {, transformados em } 16.61 \mathrm{C}\end{array}$} \\
\hline \multicolumn{4}{|c|}{ Região Centro-Oeste } \\
\hline \multirow{2}{*}{3.} & \multicolumn{3}{|c|}{ Instituição: Organização Não Governamental Programando o Futuro } \\
\hline & \multicolumn{2}{|c|}{ UF: Goiás } & Município: Valparaíso de Goiás \\
\hline \multicolumn{2}{|c|}{$\begin{array}{l}\text { Objetivo da } \\
\text { TS }\end{array}$} & \multicolumn{2}{|c|}{$\begin{array}{l}\text { O projeto Tratamento e Destinação Correta de Lixo Eletrônico, desenvolvido pela Programando o Futuro, visa que a } \\
\text { população, as empresas e órgãos públicos descartem corretamente resíduos eletroeletrônicos. }\end{array}$} \\
\hline \multicolumn{2}{|c|}{$\begin{array}{l}\text { Descrição } \\
\text { da TS }\end{array}$} & \multicolumn{2}{|c|}{$\begin{array}{l}\text { Receber e catalogar, e posteriormente desmontar e separar os equipamentos por tipo de resíduo. Geralmente são } 17 \text { os } \\
\text { tipos de resíduos, em especial as placas de circuito impresso, o plástico, o ferro, o alumínio e o cobre. Após isso, há a } \\
\text { devida orientação para o tratamento dos resíduos. }\end{array}$} \\
\hline \multicolumn{2}{|c|}{$\begin{array}{l}\text { Principais } \\
\text { Entraves }\end{array}$} & \multicolumn{2}{|c|}{$\begin{array}{l}\text {-Grande volume de lixo eletroeletrônico em países emergentes, como o Brasil. } \\
\text {-Implantação do projeto em áreas do país com maior descarte deste resíduo, como sul e sudeste. }\end{array}$} \\
\hline \multicolumn{2}{|c|}{$\begin{array}{l}\text { Principais } \\
\text { Avanços }\end{array}$} & \multicolumn{2}{|c|}{$\begin{array}{l}\text {-Atualmente a rede conta com } 50 \text { unidades no Distrito Federal e entorno. } \\
\text {-Mais de } 2,5 \text { mil toneladas de resíduos já foram processados. } \\
\text {-Mais de } 20 \text { empregos já gerados. } \\
\text {-Mais de } 100 \text { vagas de estágio ofertados à comunidade. }\end{array}$} \\
\hline & Institu & o: Instit & \\
\hline 4. & UF: $M$ & ato Grosso & Município: Cuiabá \\
\hline & $\begin{array}{l}\text { tivo da } \\
\text { TS }\end{array}$ & $\begin{array}{l}\text { A TS Co } \\
\text { que diz } \\
\text { resíduos }\end{array}$ & $\begin{array}{l}\text { enta na implementação da Política Nacional de Resíduos Sólidos (PNRS), no } \\
\text { vas e associações de catadores que têm a reciclagem e a compostagem dos } \\
\text { us associados. }\end{array}$ \\
\hline & $\begin{array}{l}\text { crição } \\
\text { TS }\end{array}$ & $\begin{array}{l}\text { O projet } \\
\text { comunid } \\
\text { maioria }\end{array}$ & $\begin{array}{l}\text { resíduos e horta, no propósito de evitar agressão ambiental e gerar renda para } \\
\text { ade de geração de renda para um grupo de chefes de família, formada em sua } \\
\text { paço Vitória. }\end{array}$ \\
\hline & $\begin{array}{l}\text { cipais } \\
\text { raves }\end{array}$ & $\begin{array}{l}\text {-Mobiliz } \\
\text {-Capacit } \\
\text {-Organiz }\end{array}$ & $\begin{array}{l}\text { onamento da TS. } \\
\text { lagem. }\end{array}$ \\
\hline
\end{tabular}




\begin{tabular}{|c|c|c|c|}
\hline \multicolumn{2}{|c|}{$\begin{array}{l}\text { Principais } \\
\text { Avanços }\end{array}$} & \multicolumn{2}{|c|}{$\begin{array}{l}\text { - Entre os anos de } 2013 \text { e } 2016 \text { a TS gerou } \mathrm{R} \$ 750.000,00 \text {. Desta receita, } 60 \% \text { foram distribuídos entre } 25 \text { cooperados. } \\
\text { Durante esse período processou - se } 14.000 \text { Toneladas de resíduos e comercializou mais de } 500.000 \text { pés de hortaliças. }\end{array}$} \\
\hline \multicolumn{4}{|r|}{ Região Sudeste } \\
\hline \multirow{2}{*}{5.} & \multicolumn{3}{|c|}{ Instituição: Prefeitura Municipal de Glaucilândia, Emater, Codema, e as Associações Comunitárias } \\
\hline & \multicolumn{2}{|c|}{ UF: Minas Gerais } & Município: Glaucilândia \\
\hline \multicolumn{2}{|c|}{$\begin{array}{l}\text { Objetivo da } \\
\text { TS }\end{array}$} & \multicolumn{2}{|c|}{$\begin{array}{l}\text { A TS Reciclar: Menos Lixo, Mais Segurança Alimentar tem como princípio a limpeza dos quintais através da coleta } \\
\text { seletiva de resíduos sólidos (metal, plástico, ferro velho, papelão) e óleo saturado. }\end{array}$} \\
\hline \multicolumn{2}{|c|}{$\begin{array}{l}\text { Descrição } \\
\text { da TS }\end{array}$} & \multicolumn{2}{|c|}{$\begin{array}{l}\text { Destinação correta dos resíduos coletados e a promoção da troca destes resíduos por mudas frutíferas, pintinhos ou } \\
\text { sementes de hortaliças. A Reciclar conscientiza os agricultores, promove a produção de alimentos a custo zero e a } \\
\text { segurança alimentar, proporciona a diversificação de alimentos no quintal, melhora a renda, diminui: focos de dengue, } \\
\text { acidentes domésticos, mortalidade de animais pela ingestão de plástico e a contaminação do lençol freático e leitos dos } \\
\text { córregos e rios. }\end{array}$} \\
\hline \multicolumn{2}{|c|}{$\begin{array}{l}\text { Principais } \\
\text { Entraves }\end{array}$} & \multicolumn{2}{|c|}{$\begin{array}{l}\text {-Integrar a comunidade rural no projeto, através da promoção ambiental e da qualidade de vida. } \\
\text {-Equipamentos necessários, como: balança, Equipamento de Proteção Individual, dentre outros. }\end{array}$} \\
\hline \multicolumn{2}{|c|}{$\begin{array}{l}\text { Principais } \\
\text { Avanços }\end{array}$} & \multicolumn{2}{|c|}{$\begin{array}{l}520 \text { agricultores atendidos sendo } 85 \% \text { de mulheres e jov } \\
\text {-Reciclados coletados com destinação correta: } 7.500 \mathrm{~kg} \\
\text { Bateria; } 2800 \mathrm{~kg} \text { Papelão; Coleta de } 220 \text { litros de óleo sa } \\
\text {-Diminuição em 90\% de focos de dengue na zona rural }\end{array}$} \\
\hline \multirow{2}{*}{6.} & \multicolumn{3}{|c|}{ Instituição: Instituto Ecob } \\
\hline & \multicolumn{2}{|c|}{ UF: Minas Gerais } & Município: Belo Horizonte \\
\hline \multicolumn{2}{|c|}{$\begin{array}{l}\text { Objetivo da } \\
\text { TS }\end{array}$} & \multicolumn{2}{|c|}{$\begin{array}{l}\text { A TS, Rede de Logística Reversa do Banner, mobiliza, sensibiliza e articula organizações para produzirem de forma } \\
\text { coletiva soluções, conhecimento e debates sobre a gestão responsável dos resíduos, além de promover e apoiar a logística } \\
\text { reversa de banners. }\end{array}$} \\
\hline \multicolumn{2}{|c|}{$\begin{array}{l}\text { Descrição } \\
\text { da TS }\end{array}$} & \multicolumn{2}{|c|}{$\begin{array}{l}\text { Transformar os banners descartados em matéria prima para produção de bolsas, pastas e crachás, entre outros produtos. } \\
\text { Espera-se que a matéria prima seja utilizada por cooperativas, projetos sociais de geração de renda, artistas, escolas, etc } \\
\text { para produção de produtos diversos. }\end{array}$} \\
\hline \multicolumn{2}{|c|}{$\begin{array}{c}\text { Principais } \\
\text { Entraves }\end{array}$} & \multicolumn{2}{|c|}{$\begin{array}{l}\text {-Local adequado para acolhimento e estocagem dos banners recebidos. } \\
\text {-Pessoas treinadas para o acolhimento dos materiais. } \\
\text {-Site para disseminação da REDE, informações aos usuários e contato direto com os doadores. } \\
\text {-Veículo adequado para carga - para suporte à coleta dos banners e logística de produção. } \\
\text {-Sistema de monitoramento da rede de logística reversa do banner. }\end{array}$} \\
\hline \multicolumn{2}{|c|}{$\begin{array}{c}\text { Principais } \\
\text { Avanços }\end{array}$} & \multicolumn{2}{|c|}{$\begin{array}{l}\text {-21.000 } \mathrm{m}^{2} \text { de banners foram reutilizados. } \\
\text {-Do total de organizações, } 300 \text { atuaram no processo de logística reversa. } \\
\text {-Cerca de } 140 \text { mulheres foram treinadas e, destas, } 36 \text { famílias foram beneficiadas com geração de renda. Atualmente, } 20 \\
\text { mulheres permanecem no projeto, atuando como costureiras e assistentes de produção. O incremento de renda destas } \\
\text { mulheres é de } \mathrm{R} \$ 500,00 \text { por mês, aproximadamente. }\end{array}$} \\
\hline \multirow{2}{*}{7.} & \multicolumn{3}{|c|}{ Instituição: P. B. Z } \\
\hline & \multicolumn{2}{|c|}{ UF:São Paulo } & Município: Dois Córregos \\
\hline \multicolumn{2}{|c|}{$\begin{array}{l}\text { Objetivo da } \\
\text { TS }\end{array}$} & \multicolumn{2}{|c|}{$\begin{array}{l}\text { O Reciclo é um programa de responsabilidade socioambiental que contribui no correto destino do lixo e na recuperação } \\
\text { das bacias dos rios da região. Funciona com a adesão dos colaboradores da Zanzini e da comunidade, particularmente } \\
\text { crianças e adolescentes, à coleta seletiva e reciclagem do lixo. }\end{array}$} \\
\hline \multicolumn{2}{|c|}{$\begin{array}{l}\text { Descrição } \\
\text { da TS }\end{array}$} & \multicolumn{2}{|c|}{$\begin{array}{l}\text { Reciclagem de materiais e reaproveitamento dos resíduos produtivos; utilização de fontes de energia alternativa; parcerias } \\
\text { com a comunidade na preservação ambiental; geração de renda para a comunidade; divulgação de indicadores, balanços } \\
\text { sociais, planos estratégicos, valores e princípios ambientais. }\end{array}$} \\
\hline \multicolumn{2}{|c|}{$\begin{array}{l}\text { Principais } \\
\text { Entraves }\end{array}$} & \multicolumn{2}{|c|}{$\begin{array}{l}\text { - Área de } 375 \mathrm{~m} 2 \text { para: recebimento e seleção; pesagem; armazenamento de material; prensagem do material; } \\
\text { armazenamento de fardos; venda de material. } \\
\text {-Empilhadeira; automóveis para coleta; e três prensas para beneficiar e embalar corretamente os materiais. }\end{array}$} \\
\hline \multicolumn{2}{|c|}{$\begin{array}{l}\text { Principais } \\
\text { Avanços }\end{array}$} & \multicolumn{2}{|c|}{$\begin{array}{l}\text {-Foi feita a reciclagem de } 1.493 \text { toneladas de lixo, que deixaram de ser despejadas na Natureza, e o auxílio educacional } \\
\text { para aproximadamente } 200 \text { colaboradores da Zanzini Móveis. Foram doados bicicletas e brindes para os alunos que se } \\
\text { destacaram no Programa. As escolas conveniadas receberam recursos financeiros, paisagismo e equipamentos. }\end{array}$} \\
\hline & & o: Fund & \\
\hline o. & & & \\
\hline
\end{tabular}




\begin{tabular}{|c|c|c|c|}
\hline \multicolumn{2}{|c|}{$\begin{array}{l}\text { Objetivo da } \\
\text { TS }\end{array}$} & \multicolumn{2}{|c|}{$\begin{array}{l}\text { ta Seletiva Solidária e Reciclagem do Óleo De Cozinha Residual, visa promover a troca destes resíduos } \\
\text { por material de limpeza. }\end{array}$} \\
\hline \multicolumn{2}{|c|}{$\begin{array}{l}\text { Descrição } \\
\text { da TS }\end{array}$} & \multicolumn{2}{|c|}{$\begin{array}{l}\text { Capacita moradores a produzir artesanato, eco-sabão e velas artesanais a partir dos resíduos. Gera trabalho, renda, } \\
\text { salubridade e conscientização ambiental. }\end{array}$} \\
\hline \multicolumn{2}{|c|}{$\begin{array}{l}\text { Principais } \\
\text { Entraves }\end{array}$} & \multicolumn{2}{|c|}{$\begin{array}{l}\text {-Falta de material permanente, de equipamentos específicos e Equipamento de Proteção Individual (EPI). } \\
\text {-Material Consumo, como por exemplo, folders, faixas e cartazes para divulgar a TS. }\end{array}$} \\
\hline \multicolumn{2}{|c|}{$\begin{array}{l}\text { Principais } \\
\text { Avanços }\end{array}$} & \multicolumn{2}{|c|}{$\begin{array}{l}42.191 \text { litros de óleo trocados por } 12.168 \text { unidades de material de limpeza, economizando aproximadamente } R \$ \\
21.100,00 \text {. O projeto capacitou } 10 \text { agentes ambientais e realizou } 16 \text { oficinas de eco sabão e velas artesanais. Instalação de } \\
34 \text { postos de coleta de óleo residual e cadastro de cerca de } 760 \text { participantes que contribuíram para o recolhimento de } \\
\text { cerca de } 90 \text { toneladas de recicláveis que foram trocados por } 16.297 \text { unidades de alimentos. Este quantitativo foi revertido } \\
\text { em mantimentos no valor aproximado de } \mathrm{R} \$ 46.000,00 \text {. }\end{array}$} \\
\hline \multirow{2}{*}{9.} & \multicolumn{3}{|r|}{ ação Profissional e Ética dos Socialmente Excluídos (INCAPESE) } \\
\hline & \multicolumn{2}{|c|}{ UF:Minas Gerais } & Município: Montes Claros \\
\hline \multicolumn{2}{|c|}{$\begin{array}{l}\text { Objetivo da } \\
\text { TS }\end{array}$} & \multicolumn{2}{|c|}{$\begin{array}{l}\text { A Tecnologia Social "Gente não é Sucata" objetiva criar alternativas de geração de renda com desenvolvimento pessoal } \\
\text { através da transformação do lixo em arte. }\end{array}$} \\
\hline \multicolumn{2}{|c|}{$\begin{array}{l}\text { Descrição } \\
\text { da TS }\end{array}$} & \multicolumn{2}{|c|}{$\begin{array}{l}\text { Transformar significativamente os espaços urbanos e levar arte através do desenvolvimento sustentável do protagonismo } \\
\text { juvenil e das mulheres, da geração de renda juntamente com a gestão de RS são as ferramentas metodológicas } \\
\text { reaplicáveis para efetivação da TS que permite uma impactante transformação socioambiental. }\end{array}$} \\
\hline \multicolumn{2}{|c|}{$\begin{array}{l}\text { Principais } \\
\text { Entraves }\end{array}$} & \multicolumn{2}{|c|}{$\begin{array}{l}\text {-Recursos humanos: pessoas especializadas para coordenar a TS. } \\
\text {-Materiais: reutilizáveis e para o desenvolvimento da linha de produtos } \\
\text {-Equipamentos: Notebook, compressor p/ pintura, máquina de solda, ferramentas de serralheria/marcenaria. }\end{array}$} \\
\hline \multicolumn{2}{|c|}{$\begin{array}{l}\text { Principais } \\
\text { Avanços }\end{array}$} & \multicolumn{2}{|c|}{$\begin{array}{l}\text { Nas vivências das Cinco edições do Natal Reciclado participaram mais de } 50 \text { jovens e seus familiares. Os jovens puderam } \\
\text { desenvolver grandes produções de brindes artesanais para mais de } 10 \text { grandes empresas brasileiras. Por fim, foram mais } \\
\text { de } 100 \text { Grupos capacitados em } 20 \text { anos. Os jovens e mulheres são os que deixaram impressões e resultados mais fortes. }\end{array}$} \\
\hline \multirow{2}{*}{10.} & \multicolumn{3}{|c|}{ Instituição: Movimento de Pimpadores } \\
\hline & \multicolumn{2}{|c|}{ UF: São Paulo } & aulo \\
\hline \multicolumn{2}{|c|}{$\begin{array}{l}\text { Objetivo da } \\
\text { TS }\end{array}$} & \multicolumn{2}{|r|}{14 pelo PimpMy Carroça, que tem por missão dar visibilidade e reconhecimento à } \\
\hline \multicolumn{2}{|c|}{$\begin{array}{l}\text { Descrição } \\
\text { da TS }\end{array}$} & \multicolumn{2}{|r|}{$\begin{array}{l}\text { inalidade transformar carroças em obra de arte, dando qualidade de vida e melhorando a } \\
\text { materiais recicláveis. }\end{array}$} \\
\hline \multicolumn{2}{|c|}{$\begin{array}{l}\text { Principais } \\
\text { Entraves }\end{array}$} & \multicolumn{2}{|c|}{$\begin{array}{l}\text {-Engajamento da sociedade civil. } \\
\text {-Todo o processo depende do engajamento de Pimpadores (voluntários realizam a reforma da carroça) e campanha de } \\
\text { crowndfunding (doadores). }\end{array}$} \\
\hline \multicolumn{2}{|c|}{$\begin{array}{l}\text { Principais } \\
\text { Avanços }\end{array}$} & \multicolumn{2}{|c|}{$\begin{array}{l}\text {-O Pimpex já esteve em mais de } 50 \text { cidades de } 14 \text { países. } \\
\text {-Mais de } 320 \text { catadores/as foram atendidos em } 101 \text { edições do Pimpex, envolvendo mais de } 10.000 \text { pessoas. } \\
\text {-Maior visibilidade e reconhecimento social dos catadores atendidos. } \\
\text {-Diminuição em até } 80 \% \text { dos acidentes de trabalho. } \\
\text {-Aumento em cerca de } 30 \% \text { da renda mensal dos catadores/as (Cataki). } \\
\text {-Engajamento social. }\end{array}$} \\
\hline \multirow{2}{*}{11.} & \multicolumn{3}{|c|}{ Instituição: Ins } \\
\hline & UF:Esp & rito Santo & Município:Vila Velha \\
\hline \multicolumn{2}{|c|}{$\begin{array}{l}\text { Objetivo da } \\
\text { TS }\end{array}$} & \multicolumn{2}{|c|}{$\begin{array}{l}\text { A Unidade Produtiva de Sabão Ecológico Verde Vida é uma iniciativa de geração de renda e Economia Solidaria do } \\
\text { Instituto Verde Vida, organização sem fins lucrativos com atuação na região da Bacia do Rio Aribiri em Vila Velha/ES. }\end{array}$} \\
\hline \multicolumn{2}{|c|}{$\begin{array}{l}\text { Descrição } \\
\text { da TS }\end{array}$} & \multicolumn{2}{|c|}{$\begin{array}{l}\text { Produzir o sabão ecológico através da reciclagem do óleo residual de fritura (ORF), coletado pelos moradores da região. } \\
\text { O Grupo Produtivo é composto por membros da comunidade, com produção assistida por um químico do IFES e } \\
\text { autogerido pelo próprio grupo. A iniciativa propõe formação social e técnica continuada. }\end{array}$} \\
\hline & & onst & $\begin{array}{l}\text { organização para trabalhar com produtos químicos. Este laboratório deve ter uma } \\
\text { ustor e bancadas. Os equipamentos para fabricação do sabão são tachos, formas, } \\
\text { para embalar o produto e EPI's. }\end{array}$ \\
\hline & & - Colet & óleo e produção de 500 barras de sabão. \\
\hline
\end{tabular}




\begin{tabular}{|l|l|l|}
\hline \multicolumn{3}{|l|}{ Região Sul } \\
\hline \multirow{2}{*}{ 12. } & \multicolumn{2}{|c|}{ Instituição: Instituto Redecriar (Reciclando a Cidadania em Rede Interdisciplinar) } \\
\cline { 2 - 3 } & UF:Rio Grande do Sul & Município:Porto Alegre \\
\hline $\begin{array}{l}\text { Objetivo da } \\
\text { TS }\end{array}$ & $\begin{array}{l}\text { A TS Joias Sustentáveis têm como foco o empoderamento da população atendida na medida em que são capacitados } \\
\text { como multiplicadores da TS. População essa, constituída por moradores de residenciais de 11 estados do Brasil, } \\
\text { contemplados com a Política Habitacional-Programa Minha Casa Minha Vida. }\end{array}$ \\
\hline $\begin{array}{l}\text { Descrição } \\
\text { da TS }\end{array}$ & $\begin{array}{l}\text { Reaproveitamento de embalagens plásticas, que possuem um tempo de decomposição de aproximadamente 500 anos, } \\
\text { reduzindo assim, o volume de descartes em aterros sanitários. }\end{array}$ \\
\hline $\begin{array}{l}\text { Principais } \\
\text { Entraves }\end{array}$ & $\begin{array}{l}\text { Pessoas especializadas, infraestrutura para repasse de conhecimento, ferramentas, materiais reaproveitáveis, materiais } \\
\text { didáticos e recursos humanos. }\end{array}$ \\
\hline $\begin{array}{l}\text { Principais } \\
\text { Avanços }\end{array}$ & $\begin{array}{l}\text {-Constituição de grupos de produção e até de associações comunitárias. Foram aproximadamente 420 multiplicadores } \\
\text { capacitados em 20 residenciais de 11 estados brasileiros que tiveram acesso a conteúdos socioambientais, de } \\
\text { empreendedorismo social e que experimentaram relações sociais de cooperação. }\end{array}$ \\
\hline
\end{tabular}

Fonte: TRANSFORMA! (2021); Fonte: Autores (2022).

Em relação aos resultados encontrados, notou-se que a região Sudeste apresentou maior porcentagem de experiências certificadas no país, aproximadamente 58\%. As TS foram desenvolvidas por prefeituras, empresas e institutos, ou seja, observa-se que tanto a iniciativa privada quanto a pública, atuam de forma articulada para o fortalecimento das TS nessa região. As regiões Nordeste e Centro-Oeste tiveram porcentagens de 17\%. A região Sul representou apenas $8 \%$ do total das TS que beneficiam indiretamente os cooperados/associados, enquanto na região Norte não foram encontradas nenhuma experiência certificada pela FBB, que através do apoio público ou privado propiciassem benefícios para as cooperativas e associações de catadores de materiais recicláveis.

\subsection{A realidade amazônica na conjuntura das TS a partir da análise da matriz regionalizada}

Após a identificação das TS que foram desenvolvidas diretamente com as cooperativas e associações e das que não foram, mas que as beneficiam indiretamente, foi possível se analisar a distribuição espacial dessas TS com relação a Amazônia brasileira (Figura 5). 
Figura 5 - Brasil: Distribuição espacial das experiências implementadas por meio das TS selecionadas, no âmbito das cooperativas/associações de catadores de materiais recicláveis, e das TS indiretamente ligadas as cooperativas/associações.

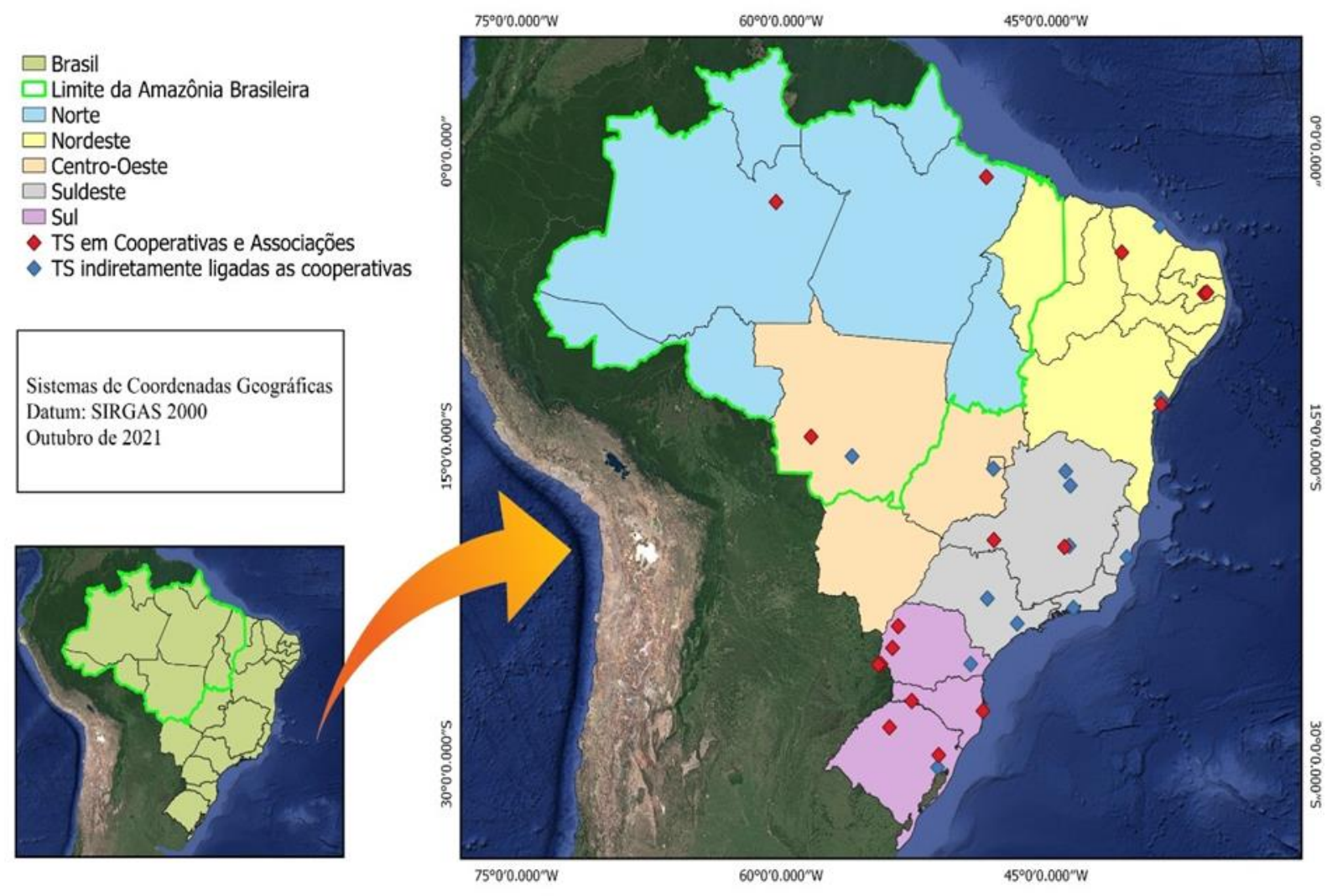

Fonte: Autores (2022).

Em relação as TS desenvolvidas diretamente nas ou com as cooperativas, foi observado o registro de três experiências na Amazônia brasileira, localizados nos municípios de: Ananindeua (Pará), Manaus (Amazonas) e Tangará da Serra (Mato Grosso). Os principais entraves relatados na aplicação dessas TS foram: a insuficiência de equipamentos de proteção individual (EPI) para os colaboradores, a falta de equipamentos adequados para o beneficiamento dos materiais coletados, e a burocracia dos órgãos públicos no processo de implantação da coleta seletiva e da gestão do processo. Com relação aos principais avanços destacam-se: a consolidação das organizações envolvidas, maior participação democrática, maior autonomia dos envolvidos com relação a tomada de decisões, e organização da sociedade e do poder público local para a implantação de coleta seletiva.

É possível notar na Figura 3 a carência de TS relacionadas a iniciativas públicas e privadas que beneficiem os cooperados e associados, mesmo que de forma indireta. Apenas uma experiência certificada relacionada a materiais recicláveis foi encontrada, no município de Cuiabá (Mato Grosso).

Ao se realizar a somatória dos dois tipos de TS (as que foram desenvolvidas diretamente com as cooperativas e associações e as que não foram, mas que mesmo assim as beneficiam indiretamente) obtêm-se o total de 29 experiências de TS identificadas no Brasil, e ao se fazer a distribuição regionalizada dessas TS, é possível se observar que a Amazônia Brasileira, que abrange cerca de 58,9\% do território nacional, possuí aproximadamente apenas 10\% do total de TS catalogadas nesta pesquisa.

\section{Discussão}

Com a construção da matriz apresentada nos resultados, foram identificados múltiplos e compostos objetivos a serem alcançados através das TS, entre os quais tiveram destaque o anseio pela melhoria de qualidade de vida e renda dos 
trabalhadores das cooperativas e associações. A predominância desses desígnios pode ser explicada por todo histórico de marginalização, condições precárias de trabalho e vida as quais estes indivíduos foram e estão expostos ainda hoje, devido a predominância de mecanismos convencionais de tecnologias, produção e desenvolvimento. A atuação de modelos cooperativistas e associativistas, robustecem os paradigmas da economia solidária que é uma ferramenta de fundamental valor para o alcance da inclusão social e consequentemente dos objetivos propostos as TS (Francischetto \& Pinheiro, 2016). Assim, em concordância ao que afirma Dagnino (2014), os empreendimentos solidários, tais como os das cooperativas e associações, são peças indispensáveis para a consolidação de modelos de desenvolvimento mais socialmente justos e ambientalmente responsáveis. Contudo, estes modelos tornam-se inviáveis sem a real atuação e sensibilização das esferas institucionais do estado em parceria com a sociedade em geral (Dagnino, 2014).

A partir da análise das informações contidas na matriz (Quadro 2), foi possível o reconhecimento da distribuição geográfica de experiências brasileiras de TS no âmbito das cooperativas e associações de catadores de materiais recicláveis, onde foi identificado que entre os 26 estados que constituem o Brasil, somente 10 possuem o registro de TS desenvolvidas diretamente com as cooperativas e associações. Em relação a Amazônia brasileira, das 17 TS catalogadas, somente três experiências estão situadas na região (aproximadamente 18\% do total), localizadas mais especificamente, nos municípios de Ananindeua (Pará), Manaus (Amazonas) e Tangará da Serra (Mato Grosso).

A baixa porcentagem na região amazônica não foi diferente em comparação as TS associadas as iniciativas privadas ou públicas que beneficiem mesmo que de forma indireta as associações e cooperativas, somente uma experiência foi apontada no município de Cuiabá (Mato Grosso), enquanto a região Sudeste possui 7 TS nessa categoria, ou seja, aproximadamente 58\% das TS que beneficiam indiretamente as cooperativas e associações estão concentradas em uma única região do país, e quando realizada a união dos dois tipos de TS catalogadas (as que foram desenvolvidas diretamente com as cooperativas e associações e as que não foram, mas que mesmo assim as beneficiam indiretamente), é quantificado que a Amazônia Brasileira, que abrange mais da metade do território nacional (aproximadamente 58,9\%), e é fonte de tantas riquezas para a federação, possui somente cerca de $10 \%$ das experiências de TS desenvolvidas e registradas no âmbito das cooperativas e associações de catadores de materiais recicláveis.

Os baixos percentuais de TS identificadas na região amazônica, escancaram a comprovada ineficiência na integração estratégica dos atores (organizações privadas, públicas e a comunidade) e semeiam o seguinte questionamento: quais os reais motivos que impedem que essa integração aconteça e as TS sejam desenvolvidas? Com base nas pesquisas realizadas, é cabível a citação de duas possíveis respostas para essa pergunta.

A primeira é baseada na construção histórica do território amazônico, que é marcado por grandes ciclos extrativistas, e mesmo atualmente continua sendo tratado como uma infindável fonte de minérios e riquezas. Constantemente explorada, a Amazônia tem sua população nativa desamparada, desarticulada e exposta aos piores índices de saneamento básico no Brasil, estando assim a mercê da geração do lucro a qualquer custo e totalmente inapta para cobrar respostas e ações efetivas do poder público, para a modificação deste cenário. Loureiro (2002), afirma que mesmo quando houve grandes investimentos na região, o desenvolvimento socialmente justo nunca foi o objetivo, mas sim a exploração de mais riquezas em favor da Federação. Para sintetizar este primeiro pensamento, a integração dos atores não acontece devido o fato de ser mais interessante economicamente para organizações privadas e públicas, que não haja o empoderamento social da população amazônica, e esta continue passiva diante de toda a exploração natural que aflige a região. Para Becker (2005), a sociedade civil articulada é fundamental para que as reivindicações aconteçam.

A segunda resposta propícia ao questionamento gerado, é relacionada a atual inexistência de uma legislação que defina a TS, e de fato norteie os objetivos, instrumentos e papéis cabíveis a cada ator. Um referencial oficial que sirva como base para as entidades que desejem desenvolver a TS de forma adequada, para que a comunidade acadêmica entenda sua 
obrigação dentro deste cenário e ademais, determine a inclusão da TS no desenvolvimento de políticas públicas. A expectativa da resolução deste problema está na aprovação da PNTS que foi remetida à câmara dos deputados, onde encontra-se desde 2015. Dagnino, Cavalcanti e Costa (2016), ressaltam a necessidade do fortalecimento do saber que é no Estado (e não fora dele e da política) que se podem encontrar soluções para os desafios do desenvolvimento econômico e do avanço social.

Através da Tabela 1 foi possível verificar que entre os 11 principais entraves enfrentados antes e durante a aplicação da TS pelas cooperativas e associações no Brasil, 5 destacam-se por sua maior incidência, são eles: a falta de capacitação entre os trabalhadores (29,4\%); a falta de infraestrutura; insuficiência de recursos para a operacionalização da TS; a inexistência ou ineficiência da coleta seletiva; e a baixa participação da população nas ações, todos estes com 17,6\%. Resultados estes que estão em consonância com as dificuldades enfrentadas pelas cooperativas e associações de catadores de materiais recicláveis de acordo com os levantamentos realizados por Gutierrez e Zanin (2013), Santos, Deus e Battistelle (2018), que citam, entre outros desafios, a baixa qualificação dos trabalhadores e a deficiência tanto infraestrutural, como técnica.

Em relação a Amazônia brasileira, quando analisado os entraves enfrentados pelas cooperativas e associações, a partir das informações obtidas durante a construção da matriz regionalizada (Quadro 1), foi possível a identificação que os principais problemas enfrentados, se referem a necessidade de maior quantidade de EPI para os trabalhadores, a deficiência infraestrutural (falta de maquinários específicos para o beneficiamento dos materiais coletados), a dificuldade em lidar com o excesso de burocracia institucional e de obter apoio do poder público às organizações, estando os dois últimos fatores totalmente em contramão ao que preconiza a PNRS, que tem a integração dos catadores de materiais recicláveis como um de seus objetivos e entre seus instrumentos de consolidação, o incentivo à criação e ao desenvolvimento de cooperativas e associações de catadores de materiais recicláveis (Brasil, 2010) e corroboram a ideia lançada anteriormente, de que não há de fato interesse no ator estatal em investir ou desenvolver ações voltadas para o desenvolvimento social na região. Como consequência, tem-se a dificuldade na consolidação de um sistema socioeconômico que se desenvolva e que tenha a autonomia financeira dos participantes.

Na região Amazônica há a necessidade de uma atuação mais objetiva e intencional do Estado, pois, este pode fomentar iniciativas de prevenção e redução da geração de RS nos processos produtivos. Assim, pode a exemplo de TS aplicadas em outros municípios, consentir incentivos fiscais e financeiros para reutilização e/ou tratamento de RSU. Além disso, o Estado pode apoiar diretamente projetos em conjunto as cooperativas, que por sua vez, necessitam corrigir posturas individualizadas e falta de organização social, fatores que ressaltam ainda mais as condições precárias de trabalho na região (Brasil, 2010; Cavalheiro et al., 2019).

E por fim, foram observados quais principais avanços o desenvolvimento das TS proporcionaram em cada experiência catalogada. Todas obtiveram resultados positivos em maior ou menor escala, os benefícios na dimensão ambiental são indiscutíveis e consideráveis, mas é a predominância de registros de melhoria na qualidade de vida e renda dos trabalhadores, que caracterizam a principal premissa da TS que é transformação social. Estes resultados também demonstram que os objetivos almejados, que em sua maioria apontavam para a necessidade de aumento de renda e melhor qualidade de vida para os cooperados, foram de fato alcançados através das TS. A partir da união, capacitação e busca coletiva de melhorias, os cooperados/associados, como afirmado por Campos (2013), obtiveram destaque e visibilidade social, por desempenharem um importante papel na gestão dos RS, em níveis econômico e político. O cooperativismo e associativismo, são fundamentais na busca por melhores condições de trabalho e renda, os trabalhadores envolvidos com o setor de coleta de materiais recicláveis necessitam se organizar. Fontão e Oliveira (2020), relacionam estes fatores com a proposta da economia solidária, visto que este é um modo de produção alternativo, cujos princípios básicos são a propriedade coletiva ou associada do capital e o direito à liberdade individual.

Dessa forma, as aplicações das TS, no âmbito das cooperativas e associações abordadas, demonstram que estas são 
ferramentas desenvolvidas objetivando principalmente solucionar ou minimizar, as mazelas sociais, econômicas e ambientais a que estas populações estão historicamente expostas devido a imensa lacuna criada pela ausência de políticas públicas integradoras. Consta-se diante dos problemas identificados e das soluções desenvolvidas/adotadas, que a TS é uma metodologia ou produto, criado e/ou aplicada na interação com a população, e apropriada por ela, propiciando a inclusão social e a melhoria das condições de vida (ITS, 2007).

Corroborado a isso, de acordo com Cavalheiro et al. (2019), a TS tem como princípio a construção por meio dos diferentes saberes, portanto, a participação e o protagonismo social são de grande relevância. No que se refere as políticas públicas, é necessária a articulação com o Estado para a troca de informações, interesses e demandas. A TS, entretanto, de acordo com Costa (2013): "não é o artefato que gera a inclusão, mas a forma como é construído, com o envolvimento da comunidade". Assim, mais especificamente para a região amazônica, observa-se que além da reaplicação das técnicas, é preciso ocorrer a reflexão sobre a construção para reaplicação contextualizada e não somente padronizada, além do despertar da população quanto ao seu papel e direitos (Cavalheiro et al., 2019).

\section{Considerações Finais}

O desenvolvimento do presente estudo possibilitou a catalogação e a análise de experiências de TS observadas no escopo das cooperativas e associações de catadores de materiais recicláveis no Brasil, também propiciou uma visão regionalizada quanto a situação amazônica no que diz respeito ao tema central da pesquisa e viabilizou o conhecimento sobre objetivos, aplicações e resultados alcançados por experiências de TS.

De maneira geral, mesmo enfrentando inúmeros entraves, que vão desde a falta de capacitação e materiais básicos para o trabalho, até dificuldades com a burocracia institucional e falta de apoio, as TS catalogadas na matriz, mostraram-se capazes de atender as demandas locais das cooperativas e associações onde foram aplicadas, observou-se isso ao se comparar os objetivos e avanços alcançados de cada TS descrita. Assim, respondendo aos questionamentos iniciais desta pesquisa, podese afirmar com base nos resultados obtidos, que no âmbito das cooperativas e associações de catadores de materiais recicláveis, as TS revertem-se em benefícios socioeconômicos, para os trabalhadores e suas famílias, pois através do desenvolvimento de metodologias e produtos que preservam a sua integridade e otimizam o seu trabalho, estes sentem-se mais valorizados, buscam de forma coletiva soluções e consequentemente conseguem aumentar sua renda, gerando assim mais qualidade de vida e benefícios para o meio ambiente. Porém é necessário enfatizar que não se trata de um processo simples ou rápido, o desenvolvimento de soluções através das TS é um processo complexo, que requer profundo comprometimento dos envolvidos, pois a apropriação sobre o produto ou método gerado, pela população que será beneficiada, é alicerce para que a TS seja sustentável e eficiente, somado a estes fatores, têm-se ainda a carência de um aporte referencial oficial e de políticas públicas que de fato incentivem as TS no Brasil.

Quanto a realidade amazônica em relação aos desafios para o desenvolvimento do cooperativismo, associativismo, da economia solidária, da autossustentabilidade financeira, além da verdadeira e efetiva implementação das diretrizes instituídas pela PNRS na região. De um modo geral, os resultados demonstraram a fundamental importância da ocorrência da integração dos atores: Estado, organizações privadas e comunidade. Entretanto a realidade na Amazônia, ainda está distante de atingir essa integração. O contexto histórico da região, a estigmatizou apenas como fonte de riquezas para o resto do país, possuindo uma população exposta a grandes quadros de vulnerabilidade social, e que dificilmente consegue articular-se em prol de seus direitos. Assim, notou-se que estas condições são benéficas para os que exploram a região seguindo os modelos tradicionais de tecnologia e do lucro a qualquer custo, explicitando a falta de gestão, por parte do Estado, no que se refere ao controle de passivos ambientais, desenvolvimento de políticas públicas relacionadas a materiais recicláveis e a incentivos fiscais às cooperativas e associações. 
Entendida a importância e complexidade dos temas aqui discutidos (Tecnologias Sociais, Resíduos Sólidos, Políticas Públicas e Amazônia) almeja-se ter contribuído positivamente para que as cooperativas e associações de catadores de materiais recicláveis que estejam em busca de soluções para suas demandas, possam tomar conhecimento sobre a possibilidade de desenvolvimento ou adaptação e reaplicação de TS. E que todos que tenham acesso a este estudo (Comunidade acadêmica, poder público, a sociedade em geral), sintam-se instigados a questionar o seu papel individual dentro do modelo governamental vigente, entendendo a real necessidade da quebra de paradigmas, e uma participação mais ativa na política e na resolução da problemática socioambiental que tange toda a região amazônica de maneira tão severa e catastrófica, fomentando assim, movimentos de inclusão social e fortalecimento de políticas públicas realmente integradoras.

Para futuras pesquisas dentro dessa temática e metodologia, deixa-se como recomendação a ampliação das bases de dados consultadas.

\section{Referências}

Arantes, B. O. \& Oliveira, B. L (2013). Catadores de materiais recicláveis: cadeia produtiva e precariedade. Arquivos Brasileiros de Psicologia. 65 (3), 319 337. https://www.redalyc.org/pdf/2290/229029496002.pdf

ABRELPE (2020). Panorama de resíduos sólidos no Brasil, São Paulo. Associação Brasileira de Empresas de Limpeza Pública e Resíduos Especiais. https://abrelpe.org.br/panorama-2020/

Baumgarten, M. (2006). Tecnologias sociais e inovação social. Cattani AD, Holzmann L, organizadores. Dicionário de trabalho e tecnologia. Porto Alegre: Editora da UFRGS, 302-304.

Becker, B. K (2005). Geopolítica da Amazônia. Estudos Avançados. 19 (53), 71-83. https://www.scielo.br/j/ea/a/54s4tSXRLqzF3KgB7qRTWdg/?lang=pt

Brasil (2010). Lei no 12305/2010 - Política Nacional de Resíduos Sólidos. Diário Oficial da República Federativa do Brasil, Brasília, DF.

Castro, L. R. C. et al (2020). Panorama sanitário das populações ribeirinhas da Amazônia Brasileira e as tecnologias sociais aplicáveis. Research, Society and Development, 9 (12). https://doi.org/10.33448/rsd-v9i12.10898

Cavalheiro, A. R. R \& Gazolla, M., \& Marini, M. J (2019). Tecnologia social: contribuições à política nacional de resíduos sólidos. Revista Tecnologia e Sociedade, 15 (38). https://periodicos.utfpr.edu.br/rts/article/view/8458.

Costa, D. I (2015). Materiais recicláveis: um estudo na eco recicla e eco cooperativa em Manaus - AM-2014/2015. RELATÓRIO FINAL PIB-SA/0122/2014. MANAUS

Dagnino, R. (2014). Tecnologia Social: contribuições conceituais e metodológicas: EDUEPB, 318 p.

Dagnino, R.; Cavalcanti, P. A. \& Costa, G (2016). Gestão Estratégica Pública. São Paulo: Editora Fundação Perseu Abramo.

De Souza, M. F. B. et, al. (2015). Tecnologia Social na Reciclagem de Vidros: O Caso da Associação de Catadores e Recicladores do Município de Campina Grande. In: CONGRESSO BRASILEIRO DE ENGENHARIA SANITÁRIA E AMBIENTAL, 28 , https://abesnacional.com.br/XP/XPEasyArtigos/Site/Uploads/Evento29/TrabalhosCompletosPDF/III-519.pdf

Farias, M. H. et al. (2015). Tecnologia Social e a Valorização de Associações e Cooperativas de Catadores de Materiais Recicláveis: Estudo de Caso Sobre a Associação de Catadores de Águas Lindas, Ananindeua, Pará. Enciclopédia Biosfera, 11 (21), 3289-3299. http://www.conhecer.org.br/enciclop/2015b/multidisciplinar/tecnologia\%20social.pdf

Francischetto, G. P. P. \& Pinheiro, P. T. (2016). A política nacional de resíduos sólidos como mecanismo de fortalecimento das associações de catadores de materiais recicláveis. Derecho y cambio social. http://repositorio.fdv.br:8080/handle/fdv/596.

Gil, A. C. (2008) Métodos e técnicas de pesquisa social (6a ed.). Atlas.

Gil, A C. (2017) Como Elaborar Projetos de Pesquisa (6a ed.). Atlas.

Gouveia, N. (2012). Resíduos Sólidos Urbanos: Impactos Socioambientais e Perspectiva de Manejo Sustentável com Inclusão Social. Revista Ciência e saúde coletiva, 17 (6), pp. 1503-1510. https://www.scielo.br/j/csc/a/y5kTpqkqyY9Dq8VhGs7NWwG/?lang=pt\&format=pdf

Gonçalves, M. A. \& Silva, S. R. (2009). O programa de coleta seletiva e trabalho dos catadores de resíduos sólidos recicláveis em Nova Andradina- MS. Revista Geografia em Questão, 1 (02) 130-140. https://e-revista.unioeste.br/index.php/geoemquestao/article/download/3204/2525/0

Gualdania, C. \& Sales, M. (2016). Tecnologias sociais de convivência com o Semiárido e a racionalidade camponesa. Sustentabilidade em Debate, 7, 86-99. https://periodicos.unb.br/index.php/sust/issue/download/1370/152\#page=86

Gutierrez, R.F. \& Zanin, M (2013). A relação entre tecnologias sociais e economia solidária: um estudo de caso em uma cooperativa de catadores de resíduos. Revista Brasileira de Desenvolvimento Regional, 1 (1), 129-148. https://core.ac.uk/download/pdf/323994826.pdf.

IBGE (2021). Mapa da Amazônia Legal. https://www.ibge.gov.br/geociencias/cartas-e-mapas/mapas-regionais/15819-amazonia-legal.html?=\&t=downloads. 
Research, Society and Development, v. 11, n. 2, e51311226003, 2022

(CC BY 4.0) | ISSN 2525-3409 | DOI: http://dx.doi.org/10.33448/rsd-v11i2.26003

Loureiro, V. R (2002). Amazônia: uma história de perdas e danos, um futuro a (re)construir. Estudos Avançados, 16 (45), 107-121. https://www.scielo.br/j/ea/a/DzYjwpvT3vxySGCnwpK6BDw/?format=pdf\&lang=pt

Oliveira, G. K. L. P. \& Santos, N. (2016). Tecnologias Sociais Aplicadas a Política Nacional de Resíduos Sólidos: Gestão Integrada de Resíduos Sólidos no Campo. Revista de Direito e Sustentabilidade, 2 (1), p. 205-220. https://indexlaw.org/index.php/revistards/article/download/1039/1034

Oliveira, T. B. \& Galvão Jr, A.C. (2016) Planejamento Municipal na Gestão dos Resíduos Sólidos Urbanos e na Organização da Coleta Seletiva. Revista Engenharia Sanitária e Ambiental, 21 (1), 55-64. 10.1590/S1413-41520201600100155929

Ribeiro, L. A. \& Da Silva, M. M. P (2015). Tecnologia social para coleta e transporte de resíduos sólidos: uma contribuição ao exercício profissional de catadores de materiais recicláveis. Polêm!ca, 15 (3), 68-89. 10.12957/polemica.2015.19354

Santos, C. D. M. \& Zamora, M (2013). Impactos econômicos da Tecnologia Social de Reciclagem de Plásticos na Cooperativa de Dois Irmãos. V Simpósio Nacional de Tecnologia e Sociedade.

Santiago, L. S. \& Dias, S. M. F. (2012) Matriz de Indicadores de Sustentabilidade para a Gestão de Resíduos Sólidos Urbanos. Revista Engenharia Sanitária e Ambiental, 17 (2), 203-212. https://www.scielo.br/j/esa/a/HkLj9SJQVjtjZ4hcTnHDCCC/?lang=pt\&format=pdf

Santos, R. A; Deus, R. M \& Battistelle, R.A.G (2018). Cooperativas de reciclagem: Problemáticas e desafios para o desenvolvimento sustentável. Revista espacios, 39. https://www.revistaespacios.com/a18v39n26/a18v39n26p04.pdf

Sguarezi, S. B. et al. (2018). Inovação social em uma cooperativa de catadores em Tangará da Serra/MT. Revista Ibero Americana de Ciências Ambientais, 9 (4), 268-284. http://doi.org/10.6008/CBPC2179- 6858.2018.004.0022view=blog\&id=2117.

TRANSFORMA! (2021). Transformar realidades por meio das tecnologias sociais. Brasília. https://transforma.fbb.org.br/sobre-nos.

Veiga, T. B. et al. (2016) Construção de indicadores de sustentabilidade na dimensão da saúde para gestão de resíduos sólidos. Revista Latino-Americana de Enfermagem, 24. 10.1590/1518-8345.0635.2732 